\title{
Subjective stakeholder dynamics relationships treatment: a methodological approach using fuzzy decision-making
}

\author{
Fabio Blanco-Mesa ${ }^{1}$. Anna María Gil-Lafuente ${ }^{2}$. José M. Merigó3
}

\begin{abstract}
Since the stakeholder theory was proposed to explain the interaction among its agents, extensive approaches have been developed. However, the literature continues to suggest the development of new methodologies that allow an analysis of the dynamics and uncertainty of the relationships between each agent. In this sense, this research proposes a novel methodology for the treatment of subjective stakeholder dynamics using fuzzy decision-making. The study proposes a mathematical methodological perspective for the treatment of subjective relationships among stakeholders, which allows a predictive simulation tool to be developed for attitude and personal preferences to analyze the links among all stakeholders. A mathematical application is developed to help the decision-making process in uncertainty concerning the ordering-according-to-their-importance and linking-of-relation algorithms, which are based on notions of relation, gathering and ordering. A numerical example is proposed to understand the method's usefulness and feasibilityhe results approximate how stakeholder ambiguity and fuzziness can be managed considering the decision-maker's preference subjectivity. In addition, these results highlight the different relationships among each stakeholder, their intensity levels, the incidence linkage loops and the incidence relative on stakeholder behaviors. The main implication of this proposition is to deal with the subjective preferences provide by decision-maker to better interpret environmental and subjective factors. Furthermore, this study contributes to the strategic planning and decision-making processes for operative units within uncertain environment in the short term.
\end{abstract}

Keywords Fuzzy theory $\cdot$ Decision-making $\cdot$ Stakeholder dynamics $\cdot$ Subjectivity and incidences

Fabio Blanco-Mesa

fabio.blanco01@uptc.edu.co

Extended author information available on the last page of the article 


\section{Introduction}

Stakeholder theory has been proposed to explain and identify relationships among stakeholders (Wagner et al. 2011). Based on this theory, several analytical tools have been developed to explain stakeholder interactions. Tools for analyzing stakeholders have been focused on developing matrices, lists of criteria and attributes to understand complexity and change (Ramirez 1999). Therefore, several approaches are highlighted, such as, Instrumental (Freeman 1984, 2004, 2011; Donaldson and Preston 1995), strategy Mitchell et al. (1997), network Rowley (1997), mental models Hjortsø et al. (2005) and so on. However, they have problems defining boundaries and identifying relevant stakeholders (Ramirez 1999). Thus, these tools have been used to explain stakeholder relationships through visual schemes and to comprehend, simplify and aggregate complex information (Fassin 2007). Nevertheless, some of these models show only a static representation and do not consider change over time, heterogeneity, or static characteristics that have been criticized (Friedman and Miles 2002; Fassin 2009). In fact, stakeholders are structured by internal and external relationships, which are always in a dynamic situation with important changes affecting organizational results (Windsor 2011). Relationships between the interest groups differ, since interactions differ depending on the power and the sensitivity of their influence, and not all have the same weight and participation (Fassin 2007). In these sense, relationship structure are conformed by persons, where occur dynamic situations that affects organizational results. These dynamics involve human reasoning; attitudes, perceptions, personal appraisals, notions, value judgments and opinions have a high subjectivity and high degree of incidence on final decisionmaking, i.e. the imperfections, heterogeneous and dynamic of relationships are conditioned by human behavior. The relationships have a dynamic and uncertain process; where the dynamic process implies a change in the relationship's interaction among actors that participate in the firm's environment and uncertainty implies unexpected environmental facts, fuzzy boundaries and unclear levels of organization. Hence, stakeholder relationships and their behavior are in complex, uncertain and dynamic situation in which human reasoning is the key factor in the imperfection and heterogeneity of them. Thus, it is suitable to use new perspectives that taking into account dynamic and uncertain of the relationships based on human rationality.

Under this perspective, in the fields of mathematics and information systems, multiple methodologies have been proposed and developed that allow the treatment of uncertainty and dynamic processes. One of these fields is fuzzy decision-making. Studies on fuzzy decision-making stemmed from studies on the concepts of fuzzy sets (Zadeh 1965), fuzzy environments (Bellman and Zadeh 1970), approximate reasoning (Zadeh 1975a, b, c) and applications of fuzzy sets in decision systems (Zimmermann 1986). These studies have provided several approaches that allow a numerical process treatment of the decision-maker's subjectivity and opinion.

Based on the above, this paper proposes a novel methodology for treating stakeholder dynamics through a causal relationship. The methodology is developed 
using two algorithms-an ordering-according-to-importance algorithm and a linking-of-relations algorithm - both of which are based on notions of relation, gathering and ordering (Gil-Aluja 1999). This mathematical tool allows the study of intense and linked relationships ${ }^{1}$ (Gil-Aluja 1999) of all a stakeholders in an organization. A numerical example is proposed to demonstrate the method's usefulness and feasibility. In this case, the numerical example is focused on a mathematical assumption regarding the treatment of stakeholder relationships. The numerical example's results allow us to obtain the fuzzy subjective preference and the relative intensity between each stakeholder. These results are depicted to show the intensity of stakeholder importance and each stakeholder's relational ties in a firm's entire structure. However, the model has some limitations because it is a theoretical proposal; the data come from a mathematical assumption of subjective preference and specific information, which are only valid in the short term. This proposition's main implication is to address the decision-maker's subjectivity to allow for a more accurate interpretation of environmental and subjective factors. Furthermore, this methodology allows for a holistic assessment of the immediate firm's environment.

This paper is structured as follows. First, the theoretical framework is composed of dynamic relationships among stakeholders, which is the study's main contribution to fuzzy decision-making. Second, the methodology is defined using a mathematical model, which refers to the comparison notion and the causality and incidence of the relation concepts. Third, a mathematical application is proposed. Fourth, an illustrative example, a mathematical application model, the main results and implication and limitations are explained. Finally, the conclusions are presented.

\section{Theoretical framework}

\subsection{Dynamic relationship of the stakeholders}

Stakeholder theory has helped researchers understand the environments and relations of firms. This theory has sought to explain and predict how organizations act by considering stakeholder influences (Wagner et al. 2011). Furthermore, it has provided an account of how stakeholders act and seek to influence a firm's decision-making and behavior (Frooman 1999). In fact, stakeholder theory has

\footnotetext{
${ }^{1}$ Intense and linked relations are defined as characteristics and properties of each relationship type. Intensity considers that a connector agent is in the relationship, which allows an analysis of the convergence of the limit, periodicity and non-standardized situations that are reflected in aspects such as time, space and possible connections. Thus, relationships' behavior can be observed as time passes or a sequence happens, which can strengthen or weaken existing relationships or create new relationships. Linked considers the graphical representations of the relationships in which the direct or indirect connections are shown, i.e., the linked relationships among the different objects belonging to the graph are established. Thus, variations can be analyzed in the relations' intensities, levels or strengths to observe the behavior and the links' strengthening or degradation establishing the relationships in a period of time or in a sequence of stages.
} 
been used to develop several analytical tools as part of the strategic management approach to evaluate the environment and identify the relations among groups that constitute stakeholders (Wagner et al. 2011). According to Ramirez (1999), these tools have focused on developing matrices or lists of criteria or attributes to understand stakeholders' complex and ever-changing natures; however, these tools have difficulty defining boundaries and identifying relevant stakeholders. In this sense, from Freeman (1984), numerous stakeholder analysis approaches have been developed to aid to comprehend stakeholders behavior. In Table 1, it is presented relevant approaches and methodologies that have been proposed by several authors to explain and understand them. This review shows that stakeholder analysis has had an evolution from instrumental aspects to complex methodologies supporting on computer science and mathematics to explain stakeholder behavior. All these approaches have sought to explain stakeholder relationships visually to facilitate simplification, aggregation, and ultimately comprehension of complex information (Fassin 2007). However, some of these models have been criticized because they are static representations that do not consider change over time or heterogeneity (Friedman and Miles 2002; Fassin 2009). According to Fassin (2007), a graphical stakeholder representation should represent their imperfections and such complex realities as heterogeneity within stakeholder groups, multiple inclusion, variability in dependence among stakeholders, salience, the existence of a central place within the model, multiple linkages and network relationships. These considerations suggest that stakeholders' relationships are imperfect, heterogeneous and dynamic. In these sense, it is important to observe that relationship structure are conformed by persons, where occur dynamic situations that affects organizational results. These dynamics involve human reasoning, such as: attitudes, perceptions, personal appraisals, notions, value judgments and opinions, which have a high subjectivity and high degree of incidence on final decision-making. Hence, the imperfections, heterogeneous and dynamic of relationships are conditioned by human behavior.

Afterward, the imperfect relationships between stakeholders transform a stable environment in a complex and dynamic environment. In this sense, stakeholders are always in a dynamic situation in which important changes are occurring, possibly simultaneously, within an organiztion's internal relationship structure, thus affecting the stakeholders' organizational results and internal composition (Windsor 2011). Likewise, stakeholder dynamism should be distinguished at different levels of influence according to the relation (Donaldson and Preston 1995) and dynamic aspects in relation to the environmental level (Post et al. 2002). Dynamism occur between groups and sub-groups, in which there exist multiple interests and multiple roles (Winn 2001) at different levels and sub-levels (Fassin 2007). Furthermore, it is noteworthy that all relationships and impacts that exist among various stakeholders are not equal: a) the interaction may differ depending on the power and sensitivity of influence, and b) not all interactions carry the same weight and stake (Fassin 2007).

Based on the above, it can be considered that relationships between firms and their stakeholders are in constant changes within a dynamic and uncertain process. On the one hand, the dynamic process implies a change in the relationships among actors in the firm's environment. This process is perceived by multiple 
Subjective stakeholder dynamics relationships treatment:...

Table 1 Tools for analyzing stakeholders

\begin{tabular}{ll}
\hline Approach & Description \\
\hline Instrumental Freeman $(1984,2004,2011)$ & $\begin{array}{c}\text { It proposed a descriptive/empirical aspect, an instru- } \\
\text { mental aspect and a normative aspect }\end{array}$ \\
Instrumental (Donaldson and Preston 1995) & $\begin{array}{l}\text { It focused mainly on a descriptive, normative and } \\
\text { instrumental corporative point of view }\end{array}$ \\
Strategy Mitchell et al. (1997) & $\begin{array}{l}\text { It developed a strategic model to analyze stake- } \\
\text { holder salience based on the attributes of power, } \\
\text { legitimacy and urgency }\end{array}$
\end{tabular}

Network Rowley (1997) and Rowley and Moldove- It suggested a network approach to explain stakeanu (2003) holder interactions. This approach is focused on different relationship characteristics, which can be explained by a dyadic relationship, ego-network, multiple interaction and complete network (Sciarelli and Tani 2013)

Qualitative and Quantitative method Varvasovszky It provided guidance on how to do stakeholdand Brugha (2000) ers analysis, which includes describing how to identify and approach stakeholders and considers the use of qualitative or quantitative data collection methods for estimating stakeholder positions, levels of interest and influence around an issue

Simulation model Stave (2002)

It proposed the use of computer simulation models to improve decision-making processes

Mapping analytics Bourne and Walker (2005)

It provided a stakeholder analytical tool that allows the visualization of stakeholder power and influence through network mapping. This tool contributes to understanding how to identify and measure stakeholder impact and the significance of their potential influence

Mental model Hjorts $\emptyset$ et al. (2005)

It suggested that the five-step Rapid Stakeholder and Conflict Assessment (RSCA) methodology use cognitive mapping of stakeholders' mental models

Lange and Hehl-Lange (2005)

It introduced 3D visualization among the different interest groups to identify potential conflicts at an early stage of the planning process

Multi-criteria decision-making tool Holz et al. (2006)

It used a multi-criteria decision-making tool that allows a representation of the weighting, aspirational and holistic methods. This method includes a new tool, referred to as Target Ordering, that explores preferences through criteria targets rather than applying weights to the criteria themselves

Conflict and perceptions analysis Memon and Wilson (2007)

It used the concept of 'governance' and the related notion of 'multi-layered' forest management decision-making as an overarching framework for the analysis of conflict among stakeholder groups with contrasting perceptions

Multi-criteria analysis Finn et al. (2009)

used a multi-criteria analysis (MCA) technique to assess expert judgments about single objectives or measures, which enabled the comparison of the degree of environmental effectiveness 


\begin{tabular}{lc} 
Table 1 (continued) & Description \\
\hline Approach & It used Q methodology, which allows comparing \\
\hline Q methodology Wolsink and Breukers (2010) & catterns in stakeholder views on institutional \\
& policy, spatial planning and environmental policy \\
Influence perspective Fassin $(2009,2010)$ & management in seeking to explain the influence \\
& of social movements from the three stakeholder \\
& categories of real stakeholders, stakewatchers and \\
& stakekeepers to explain boundaries between firms \\
& and the environmental influence \\
It studied multiple relations with greater degrees of \\
variation and the intensity of influence and power, \\
which are characterized by interaction and their \\
resulting mutual influence and interdependence, \\
interconnectedness, and interrelatedness \\
It developed a systemic dynamic methodology for \\
stakeholder analysis, which seeks to capture the \\
dynamic and complex nature of environmental \\
conflicts
\end{tabular}

Source own elaboration

relations that vary greatly and differ in intensities of influence and power (Post et al. 2002; Fassin 2010; Windsor 2011).

Relationships are characterized by interaction and the resulting mutual influence and interdependence, interconnectedness, and interrelatedness (Waddock 2011; Windsor 2011). In turn, mutual influence is exerted by this interactivity, i.e., interactors have some ability to affect a factor that is core to their own or other stakeholders' status or change other factors (Waddock 2011). Hence, the nature of their interdependence will help address the influence of environmental uncertainty and determine the firm's priorities [Harrison and St. John, 1996, see in (Fassin 2009)]. In contrast, uncertainty implies unexpected environmental fea-tures, fuzzy boundaries and unclear levels of organization. First, relationships are affected by environmental features (Windsor 2011), such as the local community and media, among others (Wagner et al. 2011), which have a growing influence on firms' decisions and actions. In fact, global events and social environments have evergreater power and influence, with managerial implications that affect stakeholder relationships (Friedman and Miles 2002; Holzer 2007). Second, the boundaries and level of firms' environments within this dynamic are not clearly defined because pressure groups and regulators occupy an ambiguous position. Furthermore, organizational boundaries are becoming fuzzy through new forms of cooperation (Fassin 2009). According to Fassin (2009, 2010), boundaries between firms and their stakeholders and the environmental influence are difficult to identify and define. Additionally, idiosyncratic factors exist particular to the context that hinder such boundaries' management and analysis (Fassin 2009). 
Hence, it is shown that stakeholder relationships and their behavior are complex, uncertain and in a dynamic situation in which human rationality plays a key role, however, methodologies proposed can not be able to show the imperfection and heterogeneity of them. Thus, it is suitable to use a dynamic and uncertain perspective of the relations to propose a novel methodology using fuzzy decision-making techniques in uncertainty.

\subsection{Fuzzy decision-making}

Fuzzy decision-making has become an important field of research, with a large number of studies developing tools and methods for its treatment (Blanco-Mesa et al. 2017). The studies on fuzzy decision-making stemmed from studies of the concepts of fuzzy sets (Zadeh 1965), fuzzy environments (Bellman and Zadeh 1970), approximate reasoning (Zadeh 1975a, b, c) and applications of fuzzy sets in decision systems (Zimmermann 1986). Research on decision-making is focused on dealing with problems of multiple criteria decision-making (MCDM). Thus, fuzzy theory is incorporated into MCDM for the treatment of problems in situations with subjective uncertainty because the objectives and constraints can involve linguistic and fuzzy variables (Tzeng and Huang 2011). Hwang and Yoon (1981) suggest that the problems of multiple criteria decision-making can be classified into multiple attribute decision making (MADM) and multiple objective decision-making (MODM), and $\mathrm{Xu}$ (2015) has proposed uncertain multiple attribute decision-making (UMADM) to rank and prioritize information based on weight. The decision maker's main interest is to design the "most" feasible alternative in relation to limited resources (Chen and Hwang 1992). According to Carlsson and Fullér (1996), these methods are developed paths to find a ranking, methods that assess the relative importance of multiple attributes and fuzzy mathematical programming. Thus, several proposals have been developed, among which we can identify intuitionistic fuzzy sets (Atanassov 1986); decision-making in a fuzzy environment (Bellman and Zadeh 1970); multiple attribute decision-making (Hwang and Yoon 1981); ordered weighted averaging aggregation operators in multi-criteria decision-making (Yager 1988); families of ordered weighted aggregation (OWA) operators (Yager 1993; Merigó and Gil-Lafuente 2009; He et al. 2017); fuzzy sets (Zadeh 1965); linguistic variables and their application to approximate reasoning-I-II-III (Zadeh 1975a, b, c); fuzzy sets as a basis for a theory of possibility (Zadeh 1999); results of empirical studies in fuzzy set theory (Zimmermann 1978); fuzzy sets and decision analysis (Zimmermann et al. 1984); fuzzy sets, decision-making and expert systems (Zimmermann 1986); fuzzy preference orderings in group decision-making (Tanino 1984); group decision-making with a fuzzy linguistic majority (Kacprzyk 1986); the analytic hierarchy process (Saaty 1980, 1987, 1990) and theory of decision in uncertainty (Kaufmann and Gil-Aluja 1991, 1992, 1993, 1995; Kaufmann et al. 1994; Gil-Aluja 1996, 2000). These methods are then applied to current business issues, such as supply-chain management, investment decision-making, personnel appraisal, product redesign and service maintenance. Currently, the research field of fuzzy decision-making has branched into new areas such as computer science, engineering, science operations 
management, mathematics, economic affairs and automatic control systems (Merigó et al. 2015). Likewise, Kochenderfer (2015) highlighted statistical tools for treating decision-making under uncertainty, such as Bayesian networks as a graphical model that capture probabilistic relationships among variables, utility theory as a framework for understanding optimal decision-making under uncertainty, Markov decision processes as a method for modeling sequential problems, model uncertainty, state uncertainty, and cooperative decision-making involving multiple interacting agents.

Of the above methodologies, we highlight that developed by Gil-Aluja (1999), which broadly explores the notion of relation. This concept studies the linking of relation and the relation of causality based on the incidence concept (Kaufmann and Gil-Aluja 1988), which can be strengthened or weakened by the variation of the intensity of relations (Blanco-Mesa 2015). The intensity is expressed by membership function, and the variation is explained by the composition max-min (Gil-Aluja 1999). These concepts allow an analytical process of subjective attributes, taking into account the decision-maker's appraisal maker according to some notable characteristics, i.e. this attributes or appraisals or opinions of decision makers are considered as subjective preferences within the process. Then, in this process, subjective preferences are more significant than in other methodologies. Likewise, the subjective preferences are composed by decision-makers estimations, which are based on the quality or quantity of data received. Thus, several authors have made some applications of this methodology within business and economic fields, such as marketing (Gil-Lafuente 1997; Nicolás and Gil-Lafuente 2012), customer management relationship (CMR) (Gil-Lafuente and Luis Bassa 2011), finance (Salazar-Garza 2012; Laengle et al. 2017), strategy (Gil-Lafuente and Barcellos de Paula 2010; MartorellCunill et al. 2013), stakeholders (Gil-Lafuente and Barcellos de Paula 2013), corporate social responsibility (CSR) (Vizuete Luciano et al. 2013), the economy (GilLafuente et al. 2012a, b; Blanco-Mesa and Gil-Lafuente 2014; Blanco-Mesa and Gil-Lafuente 2017; León-Castro et al. 2018), entrepreneurship (Maqueda Lafuente et al. 2013; Blanco-Mesa et al. 2015, 2018) and sport business (Gil-Lafuente 2002; Gil-Lafuente 2008; Gil-Lafuente et al. 2012a, b; Blanco-Mesa 2015), which have been shown to be useful in decision-making in uncertainty. These applications have the advantage that the decision-maker's preferences can be assessed showing several alternatives, intensities and importance of relations. Hence, this methodology allows reflecting the decision-maker's attitudinal character maker, focusing on problems in business and economics decision-making.

\section{Methodology}

In this section, we briefly review some basic concepts about comparison notion and fuzzy relation composed by the ordering-according-to-the-importance-of-characteristics algorithm and fuzzy composition representations in a square fuzzy matrix.

The square fuzzy and comparison index

In decision-making in uncertainty, this index is used to link relations and establish the relation of incidence or causality through the nuances of their relation levels. 
The vectors are given by subjective preferences that are in turn parameterized by the ordering-according-to-importance-of-characteristics algorithm. Therefore, a square fuzzy matrix can represent the results obtained by the comparison index.

\subsection{Ordering according to the importance of characteristics algorithm}

Identifying the characteristics' importance (Gil-Aluja 1999) is a useful technique for establishing relative importance in a causality relation between two objects considering their characteristics. The characteristics' importance is composed of the dominant eigenvalue and the dominant eigenvector.

Definition 1 Matrix reciprocal $[\tilde{R}]$ collects all characteristics compared by the time it has been preferred. For each characteristic $C_{j}$ a two-by-two comparison is carried out, $C_{i}, C_{k} ; i, k=1,2, \ldots, n$ using a quotient, which determines the time that it is preferred to the other one, such as:

$$
\mu_{i k}=\frac{f_{i}}{f_{k}}, \quad i, k=1,2, \ldots, n,
$$

where $C_{i}$ represents the times is preferred to $C_{k}$.

Note that the matrix is built by collecting all $\mu_{i k}$, and it is reciprocal and coherent/consistent. It is reciprocal because it complies with $\mu_{i i}=1 ; \mu_{i k}=1 / \mu_{k i}$, where $\mu_{i k} \in R_{o}^{+}, i, k=1,2, \ldots, n$. It is coherent/consistent because it complies with $\forall i, k, l \in\{1,2, \ldots, n\} ; f_{i} / f_{k} * f_{k} / f_{l}=f_{i} / f_{l}$, i.e., $\mu_{i k} * \mu_{k l}=\mu_{i l}$.

Therefore, the matrix must comply with the transpose property, which is given by:

$$
\sum_{k=1}^{n} \mu_{i k} * f_{k}=\sum_{k=1}^{n} \frac{f_{i}}{f_{k}} * f_{k}=n * f_{i}
$$

and the proportionality property, which is given by:

$$
\frac{\mu_{i k}}{\mu_{l k}}=\frac{f_{i} / f_{k}}{f_{l} / f_{k}}=\frac{f_{i}}{f_{l}},
$$

also:

$$
\frac{\mu_{i k^{\prime}}}{\mu_{l k^{\prime}}}=\frac{f_{i} / f_{k^{\prime}}}{f_{l} / f_{k^{\prime}}}=\frac{f_{i}}{f_{l}}
$$

Therefore:

$$
\frac{\mu_{i k}}{\mu_{l k}}=\frac{\mu_{i k^{\prime}}}{\mu_{l k^{\prime}}} .
$$


Definition 2 A Dominant Eigenvalue $E_{v a}$ of dimension n, is a mapping $E_{v a}:[0,1]^{n} x[0,1]^{n} \rightarrow[0,1]$ that has an associated limit weighting vector $\lambda_{1}^{(c)}$, with $w_{j} \in[0,1]$ and $\sum_{j=1}^{n} w_{j} \geq 1$, such as:

$$
E_{v a}\left(\left\langle x_{i}, y_{k}\right\rangle, \ldots,\left\langle x_{n}, y_{m}\right\rangle\right)=\sum_{k=1}^{n} \max w_{j}\left(\mu_{i k} * y_{k}\right),
$$

where $x_{i}$ and $y_{k}$ represents the jth largest of sets $X$ and $Y$.

Therefore:

$$
\lambda_{1}^{(c)}=E_{v a} \max
$$

Definition 3 A Dominant Eigenvector $V^{(c)}$ has an associated weighting vector $\lambda_{1}^{(c)}$, with $w_{j} \in[0,1]$ and $\sum_{j=1}^{n} w_{j} \leq 1$, such as:

$$
V^{c}\left(x_{i}, y_{k}, \ldots, x_{n}, y_{m}\right)=\sum_{k=1}^{n} \frac{\left(\mu_{i k} * y_{k}\right)}{\max \left(\mu_{i k} * y_{k}\right)},
$$

and normalizing:

$$
N^{(c)}=\frac{V^{(c)}}{\sum V^{(c)}}
$$

Therefore, Relative Importance is shown within a representative of the importance matrix $[\tilde{R}]$ by each characteristic. This matrix is given by:

$$
[\tilde{R}]^{*}=N^{(c)} *[\tilde{R}]
$$

where $[\mathcal{R}]$ is the ith arguments of the set $\mathrm{X}$.

represents following fithe, protess. above, a resulting matrix $[\tilde{R}]^{*}$ is obtained, which

\subsection{The square fuzzy matrix}

The square fuzzy matrix (Gil-Aluja 1999) is useful for representing direct and indirect relationships between physical and mental objects. In decision-making in uncertainty, it is used to link relations and to establish the relation of incidence 
or causality through the nuances of their relational levels. Therefore, the distance relatives can be represented on a square fuzzy matrix:

$$
\begin{array}{ccccccc}
a & a & 户 & a_{1} & a_{2} & \cdots & a_{i} \\
a & a & a_{1} & \left(x_{1}, y_{1}\right) & \left(x_{1}, y_{2}\right) & \cdots & \left(x_{1}, y_{i}\right) \\
{[\tilde{R}]^{*}} & = & a_{2} & \left(x_{2}, y_{1}\right) & \left(x_{2}, y_{2}\right) & \cdots & \left(x_{2}, y_{i}\right), \\
a & a & \vdots & \vdots & \vdots & \cdots & \vdots \\
a & a & a_{i} & \left(x_{i}, y_{1}\right) & \left(x_{1}, y_{2}\right) & \cdots & \left(x_{i}, y_{i}\right)
\end{array}
$$

where $[\tilde{R}]^{*}$ represents the $i$ th arguments of the sets $\mathrm{X}$ and $\mathrm{Y}$.

Note that this matrix can comply with the reflexive, transitive, symmetry and fuzzy anti-symmetry properties. It is reflexive because the relation of elements of the set $x \in E$ with itself that is with $x \in E$ is total, and the main diagonal is full of 1 . Therefore, it must be accomplished with $\forall a_{i} \in E$ where $i=1,2, \ldots, n: \mu_{i j}=1, i=j$ and $\mu_{i j} \in[0,1], i \neq j$ where $a_{i}$ are the $i t h$ arguments of the set E. It is transitive because the indirect relation among the three elements of the referential $E\left(a_{i}, a_{j}, a_{k}\right)$ can be considered in the same manner, i.e., that the indirect relation between $a_{i}$ and $a_{k}$ cannot be greater than the direct relation $a_{j}$ and $a_{k}$. Therefore, it must be accomplished with $\forall a_{i}, a_{j}, a_{k} \in E: \mu_{\text {aiik }} \geq \vee\left(\mu_{\text {aiaj }} \wedge \mu_{\text {ajak }}\right)$. It is in symmetry because the intensity of the relation from $a_{i}$ to $a_{j}$ is considered the same as $a_{j}$ to $a_{i}$. Therefore, it must be accomplished with $\forall a_{i}, a_{j} \in E, a_{i} \neq a_{j}$ and $\mu_{a i}=\mu_{a j}$ where $a_{i}$ and $a_{j}$ are the ith arguments of the set E. It is fuzzy antisymmetry because the intensity of the relation from $a_{i}$ to $a_{j}$ is not considered the same as $a_{j}$ to $a_{i}$. Therefore, it must be accomplished with $\forall a_{i}, a_{j} \in E, a_{i} \neq a_{j}$ and $\mu_{i j} \neq \mu_{j i}$ or $\mu_{i j}=\mu_{j i}=0$ where $a_{i}$ and $a_{j}$ are the $i$ th arguments of the set E.

\subsection{Fuzzy composition}

Fuzzy composition or convolution max-min (Gil-Aluja 1999) is a useful technique for associating between physical and mental objects. In decision-making on uncertainty, it is used to represent the degree of belonging or the lack of association and interaction or interconnection of fuzzy relation between elements of its own set or two or more fuzzy sets. For elements of its own set or two or more fuzzy sets, the convolution max-min can be defined as follows:

Definition 4 A fuzzy composition $R \circ S$ is defined as a fuzzy relation $U x W$ and it is associated with their characteristic functions $\mu_{R}(x, y)$ and $\mu_{S}(y, z)$, which is given by composition max-min, such as:

$$
\mu_{R \circ S}(x, z)=\vee_{y \in V}\left(\mu_{R}(x, y) \wedge \mu_{s}(y, z)\right),
$$

where $(x, z) \in(\mathrm{U}, \mathrm{W})$. 
Therefore, the relative intensity is established by the convolution of the fuzzy matrix $[\tilde{R}]$ with itself. The behavior of relation can be observed through evolution over time or at no temporal stage.

Definition 5 The max-min composition of matrix $[\tilde{R}]$ is given by:

$$
\begin{gathered}
{[\tilde{R}] \circ[\tilde{R}]=[\tilde{R}]^{2}} \\
{[\tilde{R}] \circ[\tilde{R}] \circ[\tilde{R}]=[\tilde{R}]^{2} \circ[\tilde{R}]=[\tilde{R}]^{3} .}
\end{gathered}
$$

Therefore:

$$
[\tilde{R}] \circ[\tilde{R}]=[\tilde{R}]^{n} \circ[\tilde{R}]=[\tilde{R}]^{n+1},
$$

when $[\tilde{R}]^{n}=[\tilde{R}]^{n+1}$ the process is stopped.

\section{An application in a decision-making problem for stakeholder management}

In this section, we present a numerical application of the proposed model. This application is based on a mathematical assumption of subjective preference to develop a method that allows a predictive simulation tool about attitude and personal preferences. In this sense, a hypothetical mathematical example is used to explain the functionality and feasibility of the applied use in stakeholder management based on the decision-makers' preferences. Thus, the main advantage for using the ordering-importance-of-characteristics and linking-of-relations methods is that they can parameterize the importance of the information of each characteristic according to the decision-maker's preferences. This model is comprised of 5 steps (see Fig. 1); each step indicates the process that must be followed, from obtaining information to the final results.

So, it is important to highlight to understand the meaning of subjective stakeholder dynamics. Stakeholders of specific firm are structured in internal and external relationship, without their size. This structure are conformed by persons, where occur dynamic situations that affects organizational results. These dynamics involve human reasoning, such as: attitudes, perceptions, personal appraisals, notions, value judgments and opinions, which have a high subjectivity and high degree of incidence on final decision-making. This degree is called subjective preferences. These factors create an ambiguous environment in which change over time and heterogeneity converge on dynamic and uncertain process. This process implies how a firm's decisions or actions can be affected or affects stakeholders considering uncertain environment factors. Hence, when subjective preferences change, the relationship system between firm's stakeholders is less stables and certain and more dynamics and uncertainty, which modify stakeholder behavior. Likewise, if in a system take part on a great deal of agents will be more complex. Thus, subjective stakeholder dynamics consider human reasoning; presented as subjective preferences, key factor 


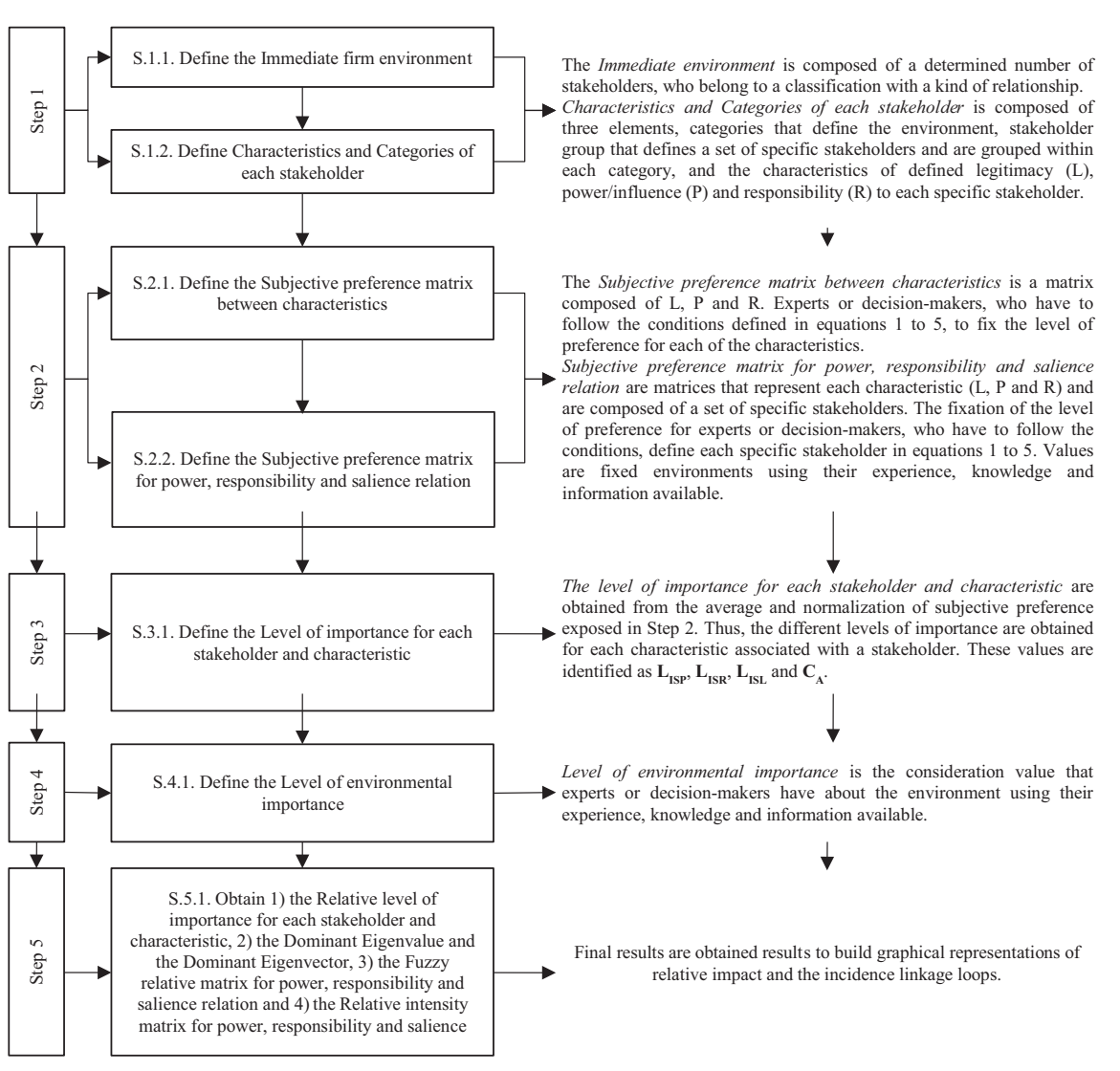

Fig. 1 Subjective stakeholder model

to modify stakeholder behavior in a dynamic and uncertain process, where a firm's decisions can be affected or affects stakeholders.

The following is a case in which a group of experts should consider the possible relationships between each interest group if a new strategic diversification plan is implemented. The main idea is to anticipate or predict stakeholder behavior when deciding to implement this new strategic plan. Thus, it supposes that a sports firm consults a group of experts to improve the decision-making process in strategic planning. Expert estimations are used to analyze how strategic planning for a new leisure program can influence the firm's relationship with each stakeholder it considers strategic. The method allows describing the linking and ordering among all characteristics. The five-step model proposed in Fig. 1 is followed:

Step 1: This step presumes that experts have defined the stakeholders of the immediate firm environment. Experts should have defined stakeholders, the kind of relationships and agents. First, this information is used to identify each stakeholder and the category to which each stakeholder belongs. Second, it allows the possible relationship to be established that can exist, which helps to define the 





Subjective stakeholder dynamics relationships treatment:...

Table 3 Characteristics and categories of each stakeholder

\begin{tabular}{|c|c|c|c|c|c|}
\hline \multirow{3}{*}{$\begin{array}{l}\text { Category } \\
\text { Real stakeholders } \\
\mathrm{R}_{\mathrm{S}}\end{array}$} & \multicolumn{2}{|c|}{ Stakeholder group } & \multicolumn{3}{|c|}{$\begin{array}{l}\text { Character- } \\
\text { istics }\end{array}$} \\
\hline & $\mathrm{a}$ & Firm & $\mathrm{L}$ & $\mathrm{P}$ & $\mathrm{R}$ \\
\hline & $\mathrm{b}$ & Employees & $\mathrm{L}$ & $\mathrm{P}$ & - \\
\hline & $\mathrm{c}$ & Business & $\mathrm{L}$ & $\mathrm{P}$ & - \\
\hline & $\mathrm{d}$ & Customers & $\mathrm{L}$ & $\mathrm{P}$ & $\mathrm{R}$ \\
\hline \multirow{3}{*}{$\begin{array}{l}\text { Stakewatchers } \\
\mathrm{S}_{\mathrm{W}}\end{array}$} & $\mathrm{e}$ & Unions and association & - & $\mathrm{P}$ & - \\
\hline & $\mathrm{f}$ & Competitors & - & $\mathrm{P}$ & - \\
\hline & $\mathrm{g}$ & Institutions and auditors & - & $\mathrm{P}$ & - \\
\hline \multirow[t]{3}{*}{$\begin{array}{l}\text { Stakekeepers } \\
\mathrm{S}_{\mathrm{K}}\end{array}$} & $\mathrm{h}$ & $\begin{array}{l}\text { Local organization and } \\
\text { Government State }\end{array}$ & $\mathrm{L}$ & $\mathrm{P}$ & $\mathrm{R}$ \\
\hline & $\mathrm{i}$ & Media and others & - & $\mathrm{P}$ & - \\
\hline & $\mathrm{j}$ & Civil Society & - & $\mathrm{P}$ & - \\
\hline
\end{tabular}

Table 4 Subjective preference matrix between characteristics

\begin{tabular}{llll}
\hline & Power & Legitimacy & Responsibility \\
\hline Power & 1 & $12 / 7$ & $11 / 2$ \\
Legitimacy & $7 / 9$ & 1 & $11 / 6$ \\
Responsibility & $2 / 3$ & $6 / 7$ & 1 \\
\hline
\end{tabular}

type of characteristic. Third, each agent is defined that belongs to each stakeholder. Thus, in this assumption, experts have defined ten stakeholders that are confirmed by sixteen agents and identified with ID from a to $\mathrm{j}$ (see Table 2). The immediate firm environment is defined using Fassin stakeholder approximation (Fassin 2009, 2010). Experts continue to have the autonomy to define and select the number of stakeholders according to the firm's need.

After that, considering the information established in Table 1, experts built categories and characteristics matrices for each stakeholder group (see Table 3). Based on stakeholders, the different categories were defined, which respond to stakeholder boundaries, i.e., environmental stakeholders (Fassin 2009, 2010). These were called real stakeholders (Rs), stakewatchers ( $\mathrm{Sw}$ ) and stakekeepers (Sk), and gathered stakeholders within a group, e.g., stakeholders e, $\mathrm{f}$ and $\mathrm{g}$ belonged to Sw. With categories and stakeholder groups defined, each of their characteristics were established according to the legitimacy of their claims (L), power/influence dominances $(\mathrm{P})$ and responsibilities $(\mathrm{R})$. These attributes conformed to stakeholder salience (Mitchell et al. 1997), which allowed a definition of the kind of relationships in three possibilities ( $\mathrm{L}$ or $\mathrm{P}$ or $\mathrm{R}$ ) to be analyzed as a unit (Salience $=\mathrm{L} \cap \mathrm{P} \cap \mathrm{R}$ ). These attributes allow analyzing the dynamic nature of stakeholder-manage relationships (Mitchell et al. 1997). In this sense, experts defined whether a stakeholder had all, some or no attributes. In this assumption $\mathbf{A Q 3}$ some stakeholders had all attributes others had some or none. Finally, each of the stakeholder characteristics was considered a property. This first step allowed us to 
Table 5 Subjective preference matrix of power relation

\begin{tabular}{lllllllllll}
\hline $\mathrm{P}$ & $\mathrm{a}$ & $\mathrm{b}$ & $\mathrm{c}$ & $\mathrm{d}$ & $\mathrm{e}$ & $\mathrm{f}$ & $\mathrm{g}$ & $\mathrm{h}$ & $\mathrm{i}$ & $\mathrm{j}$ \\
\hline $\mathrm{a}$ & 1 & 1.40 & 1.00 & 1.17 & 1.40 & 1.17 & 1.17 & 1.00 & 1.00 & 1.40 \\
$\mathrm{~b}$ & 0.71 & 1 & 0.71 & 0.83 & 1.00 & 0.83 & 0.83 & 0.71 & 0.71 & 1.00 \\
$\mathrm{c}$ & 1.00 & 1.40 & 1 & 1.17 & 1.40 & 1.17 & 1.17 & 1.00 & 1.00 & 1.40 \\
$\mathrm{~d}$ & 0.86 & 1.20 & 0.86 & 1 & 1.20 & 1.00 & 1.00 & 0.86 & 0.86 & 1.20 \\
$\mathrm{e}$ & 0.71 & 1.00 & 0.71 & 0.83 & 1 & 0.83 & 0.83 & 0.71 & 0.71 & 1.00 \\
$\mathrm{f}$ & 0.86 & 1.20 & 0.86 & 1.00 & 1.20 & 1 & 1.00 & 0.86 & 0.86 & 1.20 \\
$\mathrm{~g}$ & 0.86 & 1.20 & 0.86 & 1.00 & 1.20 & 1.00 & 1 & 0.86 & 0.86 & 1.20 \\
$\mathrm{~h}$ & 1.00 & 1.40 & 1.00 & 1.17 & 1.40 & 1.17 & 1.17 & 1 & 1.00 & 1.40 \\
$\mathrm{i}$ & 1.00 & 1.40 & 1.00 & 1.17 & 1.40 & 1.17 & 1.17 & 1.00 & 1 & 1.40 \\
$\mathrm{j}$ & 0.71 & 1.00 & 0.71 & 0.83 & 1.00 & 0.83 & 0.83 & 0.71 & 0.71 & 1 \\
\hline
\end{tabular}

Table 6 Subjective preference matrix of responsibility relation

\begin{tabular}{lllllllllll}
\hline $\mathrm{R}$ & $\mathrm{a}$ & $\mathrm{b}$ & $\mathrm{c}$ & $\mathrm{d}$ & $\mathrm{e}$ & $\mathrm{f}$ & $\mathrm{g}$ & $\mathrm{h}$ & $\mathrm{i}$ & $\mathrm{j}$ \\
\hline $\mathrm{a}$ & 1 & 1.17 & 1.40 & 0.70 & 1.17 & 1.40 & 1.00 & 0.70 & 1.00 & 1.00 \\
$\mathrm{~b}$ & 0.86 & 1 & 1.00 & 0.50 & 0.83 & 1.00 & 0.71 & 0.50 & 0.71 & 0.71 \\
$\mathrm{c}$ & 0.71 & 1.00 & 1 & 0.70 & 1.17 & 1.40 & 1.00 & 0.70 & 1.00 & 1.00 \\
$\mathrm{~d}$ & 1.43 & 2,00 & 1.43 & 1 & 1.00 & 1.20 & 0.86 & 0.60 & 0.86 & 0.86 \\
$\mathrm{e}$ & 0.86 & 1.20 & 0.86 & 1.00 & 1 & 1.00 & 0.71 & 0.50 & 0.71 & 0.71 \\
$\mathrm{f}$ & 0.71 & 1.00 & 0.71 & 0.83 & 1.00 & 1 & 0.86 & 0.60 & 0.86 & 0.86 \\
$\mathrm{~g}$ & 1.00 & 1.40 & 1.00 & 1.17 & 1.40 & 1.17 & 1 & 0.60 & 0.86 & 0.86 \\
$\mathrm{~h}$ & 1.43 & 2,00 & 1.43 & 1.67 & 2,00 & 1.67 & 1.67 & 1 & 1.00 & 1.00 \\
$\mathrm{i}$ & 1.00 & 1.40 & 1.00 & 1.17 & 1.40 & 1.17 & 1.17 & 1.00 & 1 & 1.00 \\
$\mathrm{j}$ & 1.00 & 1.40 & 1.00 & 1.17 & 1.40 & 1.17 & 1.17 & 1.00 & 1.00 & 1 \\
\hline
\end{tabular}

Table 7 Subjective preference matrix of salience 
Subjective stakeholder dynamics relationships treatment:...

Table 8 Importance level for each stakeholder and characteristic

\begin{tabular}{lllllllllllll}
\hline & $\mathrm{C}_{\mathrm{A}}$ & $\mathrm{a}$ & $\mathrm{b}$ & $\mathrm{c}$ & $\mathrm{d}$ & $\mathrm{e}$ & $\mathrm{f}$ & $\mathrm{g}$ & $\mathrm{h}$ & $\mathrm{i}$ & $\mathrm{j}$ \\
\hline $\mathrm{L}_{\mathrm{ISP}}$ & 0.4454 & 0.1224 & 0.0542 & 0.0399 & 0.1215 & 0.0662 & 0.1701 & 0.1350 & 0.1357 & 0.0559 & 0.0991 \\
$\mathrm{~L}_{\mathrm{ISR}}$ & 0.3109 & 0.4178 & 0.3511 & 0.3236 & 0.2244 & 0.2800 & 0.2691 & 0.3259 & 0.4027 & 0.2548 & 0.2399 \\
$\mathrm{~L}_{\mathrm{ISL}}$ & 0.2437 & 0.2000 & 0.2000 & 0.2000 & 0.2000 & 0.0000 & 0.0000 & 0.0000 & 0.2000 & 0.0000 & 0.0000 \\
\hline
\end{tabular}

Note that $\mathrm{L}_{\mathrm{ISP}}$ (Power), $\mathrm{L}_{\mathrm{ISR}}$ (Responsibility) and $\mathrm{L}_{\mathrm{ISL}}$ (Legitimacy) have been normalized (N) to establish the weight of each stakeholder and characteristic $\left(\mathrm{C}_{\mathrm{A}}\right)$

Table 9 Environmental importance level

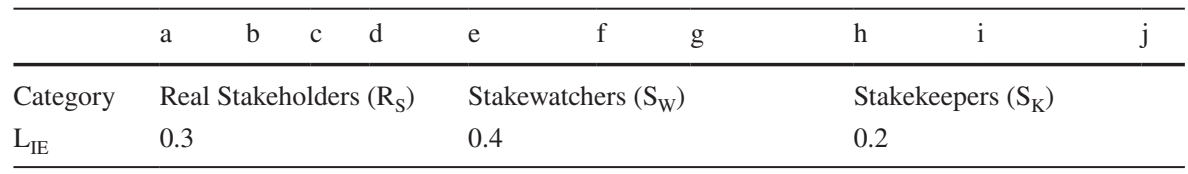

make a holistic assessment of the immediate firm environment because it considered each category and sub-set.

Step 2: Now experts have fixed each characteristic's preference level to form a subjective preference matrix. Initially, they should suggest subjective preference among power, legitimacy and responsibility (Table 4). These preferences are characterized by inverse multiplicative, i.e., if we have a number $x / y$, its inverse multiplicative is $y / x$, or if we have $x$, its inverse is $1 / x$. This characteristic represents the opposite level of subjective preference for each variable, e.g., if the subjective preference between power and legitimacy is 2 , the inverse preference between legitimacy and power is $1 / 2$. Thus, following the same procedure, subjective preference matrices of power, responsibility and salience are built for each stakeholder set (Tables 5, 6 and 7). The salience matrix considers all characteristics to establish subjective preference. Here, each of the estimates could be composed of the quality or quantity of the data received-e.g., statistics, reports, and survey information-which are used as guidance by experts.

Step 3: In this step, experts should estimate the different levels of importance ( $\mathrm{L}_{\mathrm{ISP}}, \mathrm{L}_{\mathrm{ISR}}$ and $\mathrm{L}_{\mathrm{ISL}}$ ) for each stakeholder and characteristic (CA) using the subjective preference established aboveto form the actual condition. These importance levels are obtained from the average and normalization of subjective preference (Table 8). Additionally, experts have fixed $\mathrm{L}_{\mathrm{ISL}}$ estimation, considering the existence of legal agreements.

Step 4: Here, experts have fixed the levels of environmental importance. The environment is considered as the business ecosystem in which firms develops their activities. The valuations of these levels are defined for each category using external information and the experts' experience within specific sectors. Finally, these levels are considered as weighted factors for each stakeholder (Table 9).

Step 5: To obtain the main fuzzy matrices, a technical comparison between the subjective preference matrix and the determined relative level of importance is 
considered as the starting point. In this application, each result obtained is considered a vector of importance forming a fuzzy matrix, and the multiplication of $\mathrm{L}_{\mathrm{ISP}}$, $\mathrm{L}_{\mathrm{ISL}}$ and $\mathrm{L}_{\mathrm{ISR}}$ with $\mathrm{L}_{\mathrm{IE}}$ is considered the relative importance level for each stakeholder and characteristic (RLI's).

\subsection{Results}

The following section presents the application's main results. The $\mathrm{RL}_{\mathrm{I}}$, dominant eigenvalue $\left(\mathrm{E}_{\mathrm{va}}\right)$, dominant eigenvector $\left(\mathrm{V}^{(\mathrm{c})}\right)$ and fuzzy matrices are obtained, which allows the establishment of the relative intensity among stakeholders. Thus, these algorithms are shown to be adjustable in making assumptions about the decision-maker's preference. Based on these results, the possible relationships among all stakeholders are depicted, linked and grouped. We propose a numerical example to demonstrate the proposed method's usefulness and feasibility. This methodology allows aggregating subjective information to obtain representative results. Subjective information is provided by opinions, suggestions and recommendations from experts who possess knowledge but do not know the effect of their decisions. In this case, the numerical example is focused on the mathematical assumption for the treatment of stakeholder relationships, which considers P, L, and R characteristics and Rs, Sw and Sk categories for an uncertain environment.

Initially, in this process, the relative level of importance is obtained for each stakeholder and characteristic ( $\mathrm{RL}_{\mathrm{I}}$ 's) (Table 10 ), which is the result of $\mathrm{L}_{\mathrm{ISP}}, \mathrm{L}_{\mathrm{ISL}}$ and $\mathrm{L}_{\mathrm{ISR}}$ and $\mathrm{L}_{\mathrm{IE}}$ multiplied.

After that, $\left(\mathrm{E}_{\mathrm{va}}\right)$ and $\left(\mathrm{V}^{(\mathrm{c})}\right)$ values are obtained using different $\mathrm{RL}_{\mathrm{T}} \mathrm{s}$ value (see Table 11). This table shows the values $\left(\mathrm{E}_{\mathrm{va}}\right)$ and $\left(\mathrm{V}^{(\mathrm{c})}\right)$ for power, responsibility and salience. $\mathrm{E}_{\mathrm{va}}$ and $\mathrm{V}^{(\mathrm{c})}$ values are fundamental to find fuzzy relative matrices $\left(\mathrm{FR}_{\mathrm{M}}\right)$ and intensity relative matrices $\left(\mathrm{IR}_{\mathrm{M}}\right)$.

Finally, fuzzy relative matrices $\left(\mathrm{FR}_{\mathrm{M}}\right)$ and intensity relative matrices $\left(\mathrm{IR}_{\mathrm{M}}\right)$ are defined. Initially, fuzzy relative matrices $\left(\mathrm{FR}_{\mathrm{M}}\right)$ are obtained for each subjective preference matrix (see Tables 12, 13, 14). To determine these matrices, each subjective preference matrix is multiplied with $\mathrm{V}^{(\mathrm{c})}$ normalized. These matrices allow the ambiguity and fuzziness of the stakeholders and decision-maker subjectivity to be addressed. In each matrix, number 1 defines the relationship of each stakeholder with itself in total and the decimal zero- 0.000 - defines the weakest incidence relation of appr oximately $<10^{-3}$.

Next, to obtain the intensity relative matrices $\left(\mathrm{IR}_{\mathrm{M}}\right)$, we processed each $\mathrm{FR}_{\mathrm{M}}$ using max-min composition (Tables 15, 16, 17). Max-min composition allows the simulation of relationship evolution in a short time. The results obtained for each matrix have different degrees of intensity according to the incidence levels. These different levels are considered weighted vectors. Also, in the FRM, apparently no relationships occur among some stakeholders, but in this process, these relationships have been discovered, which means that interactive relationships among stakeholders within a changing environment can be analyzed in a short time by a dynamic process. In addition, the intensity is associated with incidence and influence. 


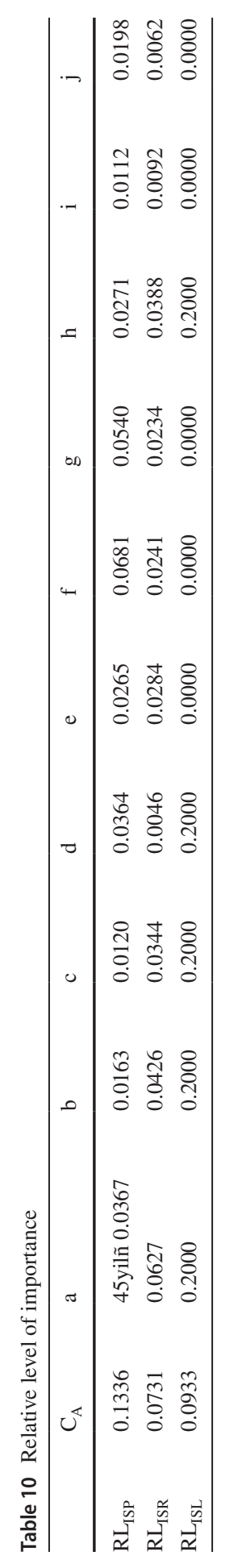


Table 11 Dominant eigenvalue and dominant eigenvector

\begin{tabular}{|c|c|c|c|c|c|c|c|c|c|}
\hline & \multicolumn{3}{|l|}{ Power } & \multicolumn{3}{|c|}{ Responsibility } & \multicolumn{3}{|c|}{ Salience } \\
\hline & $\overline{\mathrm{E}_{\mathrm{va}}}$ & $\mathrm{V}^{(\mathrm{c})}$ & $\mathrm{N}$ & $\overline{\mathrm{E}_{\mathrm{va}}}$ & $\mathrm{V}^{(\mathrm{c})}$ & $\mathrm{N}$ & $\overline{\mathrm{E}_{\mathrm{va}}}$ & $\mathrm{V}^{(\mathrm{c})}$ & $\mathrm{N}$ \\
\hline $\mathrm{a}$ & 0.327 & 0.733 & 0.110 & 0.359 & 0.928 & 0.206 & 0.165 & 0.935 & 0.165 \\
\hline b & 0.163 & 0.366 & 0.055 & 0.208 & 0.538 & 0.120 & 0.119 & 0.674 & 0.119 \\
\hline $\mathrm{c}$ & 0.159 & 0.355 & 0.053 & 0.202 & 0.523 & 0.116 & 0.117 & 0.665 & 0.117 \\
\hline d & 0.446 & 1.000 & 0.150 & 0.057 & 0.146 & 0.032 & 0.134 & 0.759 & 0.134 \\
\hline $\mathrm{e}$ & 0.254 & 0.568 & 0.085 & 0.146 & 0.378 & 0.084 & 0.058 & 0.328 & 0.058 \\
\hline $\mathrm{f}$ & 0.425 & 0.952 & 0.142 & 0.093 & 0.240 & 0.053 & 0.073 & 0.414 & 0.073 \\
\hline$g$ & 0.400 & 0.896 & 0.134 & 0.157 & 0.405 & 0.090 & 0.079 & 0.451 & 0.079 \\
\hline $\mathrm{h}$ & 0.378 & 0.848 & 0.127 & 0.386 & 1.000 & 0.222 & 0.176 & 1.000 & 0.176 \\
\hline $\mathrm{i}$ & 0.192 & 0.430 & 0.064 & 0.034 & 0.088 & 0.020 & 0.032 & 0.180 & 0.032 \\
\hline $\mathrm{j}$ & 0.239 & 0.535 & 0.080 & 0.098 & 0.254 & 0.056 & 0.048 & 0.273 & 0.048 \\
\hline
\end{tabular}

Note that the dominant eigenvector has been normalized $(\mathrm{N})$ to establish the weight of each stakeholder and salience

Table 12 Fuzzy relative matrix of power

\begin{tabular}{|c|c|c|c|c|c|c|c|c|c|c|}
\hline & $\mathrm{a}$ & $b$ & $\mathrm{c}$ & $\mathrm{d}$ & $\mathrm{e}$ & $\mathrm{f}$ & $\mathrm{g}$ & $\mathrm{h}$ & $\mathrm{i}$ & $\mathrm{j}$ \\
\hline $\mathrm{a}$ & 1 & 0.219 & 0.164 & 0.137 & 0.164 & 0.073 & 0.066 & 0.073 & 0.088 & 0.274 \\
\hline b & 0.027 & 1 & 0.088 & 0.068 & 0.055 & 0.018 & 0.011 & 0.000 & 0.000 & 0.011 \\
\hline $\mathrm{c}$ & 0.035 & 0.033 & 1 & 0.066 & 0.000 & 0.027 & 0.027 & 0.011 & 0.000 & 0.000 \\
\hline d & 0.120 & 0.120 & 0.120 & 1 & 0.150 & 0.150 & 0.449 & 0.449 & 0.000 & 0.150 \\
\hline e & 0.057 & 0.085 & 0.000 & 0.085 & 1 & 0.071 & 0.085 & 0.061 & 0.000 & 0.085 \\
\hline $\mathrm{f}$ & 0.214 & 0.427 & 0.285 & 0.142 & 0.171 & 1 & 0.085 & 0.095 & 0.142 & 0.712 \\
\hline g & 0.223 & 0.670 & 0.268 & 0.045 & 0.134 & 0.223 & 1 & 0.134 & 0.000 & 0.000 \\
\hline $\mathrm{h}$ & 0.190 & 0.000 & 0.634 & 0.042 & 0.178 & 0.190 & 0.127 & 1 & 0.127 & 0.127 \\
\hline $\mathrm{i}$ & 0.080 & 0.000 & 0.000 & 0.000 & 0.000 & 0.064 & 0.000 & 0.064 & 1 & 0.129 \\
\hline $\mathrm{j}$ & 0.032 & 0.400 & 0.000 & 0.080 & 0.080 & 0.032 & 0.000 & 0.080 & 0.040 & 1 \\
\hline
\end{tabular}

Table 13 Fuzzy relative matrix of responsibility

\begin{tabular}{|c|c|c|c|c|c|c|c|c|c|c|}
\hline & $\mathrm{a}$ & $\mathrm{b}$ & $\mathrm{c}$ & $\mathrm{d}$ & $\mathrm{e}$ & $\mathrm{f}$ & g & $\mathrm{h}$ & $\mathrm{i}$ & $\mathrm{j}$ \\
\hline $\mathrm{a}$ & 1 & 0.229 & 0.206 & 1.000 & 0.000 & 0.000 & 1.000 & 0.229 & 0.000 & 1.000 \\
\hline b & 0.108 & 1 & 0.000 & 0.598 & 0.060 & 0.000 & 0.239 & 0.000 & 0.000 & 0.478 \\
\hline $\mathrm{c}$ & 0.116 & 0.000 & 1 & 0.232 & 0.000 & 0.116 & 0.232 & 0.000 & 0.000 & 0.465 \\
\hline d & 0.006 & 0.006 & 0.016 & 1 & 0.000 & 0.000 & 0.008 & 0.006 & 0.000 & 0.000 \\
\hline e & 0.000 & 0.168 & 0.000 & 0.000 & 1 & 0.000 & 0.000 & 0.017 & 0.000 & 0.336 \\
\hline f & 0.000 & 0.000 & 0.053 & 0.000 & 0.000 & 1 & 0.000 & 0.013 & 0.000 & 0.214 \\
\hline $\mathrm{g}$ & 0.018 & 0.045 & 0.045 & 0.360 & 0.000 & 0.000 & 1 & 0.090 & 0.000 & 0.360 \\
\hline $\mathrm{h}$ & 0.200 & 0.000 & 0.000 & 1.000 & 1.000 & 0.889 & 0.222 & 1 & 0.000 & 0.222 \\
\hline $\mathrm{i}$ & 0.000 & 0.000 & 0.000 & 0.000 & 0.000 & 0.000 & 0.000 & 0.000 & 1 & 0.078 \\
\hline J & 0.011 & 0.014 & 0.014 & 0.000 & 0.014 & 0.014 & 0.014 & 0.056 & 0.014 & 1 \\
\hline
\end{tabular}


Subjective stakeholder dynamics relationships treatment:...

Table 14 Fuzzy relative matrix of salience

\begin{tabular}{|c|c|c|c|c|c|c|c|c|c|c|}
\hline & $\mathrm{a}$ & $\mathrm{b}$ & $\mathrm{c}$ & $\mathrm{d}$ & $\mathrm{e}$ & $\mathrm{f}$ & $\mathrm{g}$ & $\mathrm{h}$ & i & $\mathrm{j}$ \\
\hline $\mathrm{a}$ & 1 & 0.256 & 0.206 & 0.515 & 0.124 & 0.055 & 0.461 & 0.146 & 0.066 & 0.618 \\
\hline b & 0.083 & 1 & 0.095 & 0.371 & 0.089 & 0.020 & 0.131 & 0.000 & 0.000 & 0.249 \\
\hline $\mathrm{c}$ & 0.098 & 0.037 & 1 & 0.190 & 0.000 & 0.088 & 0.146 & 0.012 & 0.000 & 0.234 \\
\hline d & 0.067 & 0.067 & 0.087 & 1 & 0.067 & 0.067 & 0.217 & 0.214 & 0.000 & 0.067 \\
\hline e & 0.019 & 0.087 & 0.000 & 0.029 & 1 & 0.024 & 0.029 & 0.026 & 0.000 & 0.144 \\
\hline f & 0.055 & 0.109 & 0.109 & 0.036 & 0.044 & 1 & 0.022 & 0.033 & 0.036 & 0.328 \\
\hline $\mathrm{g}$ & 0.074 & 0.218 & 0.099 & 0.172 & 0.040 & 0.066 & 1 & 0.079 & 0.000 & 0.159 \\
\hline $\mathrm{h}$ & 0.211 & 0.000 & 0.440 & 0.470 & 0.564 & 0.484 & 0.176 & 1 & 0.088 & 0.176 \\
\hline $\mathrm{i}$ & 0.020 & 0.000 & 0.000 & 0.000 & 0.000 & 0.016 & 0.000 & 0.016 & 1 & 0.095 \\
\hline $\mathrm{j}$ & 0.014 & 0.126 & 0.006 & 0.024 & 0.030 & 0.016 & 0.006 & 0.048 & 0.018 & 1 \\
\hline
\end{tabular}

Table 15 Relative intensity matrix of power

\begin{tabular}{|c|c|c|c|c|c|c|c|c|c|c|}
\hline & $\mathrm{a}$ & $\mathrm{b}$ & $\mathrm{c}$ & $\mathrm{d}$ & e & $\mathrm{f}$ & $\mathrm{g}$ & $\mathrm{h}$ & $\mathrm{i}$ & $\mathrm{j}$ \\
\hline $\mathrm{a}$ & 1 & 0.274 & 0.164 & 0.137 & 0.164 & 0.137 & 0.137 & 0.137 & 0.137 & 0.274 \\
\hline $\mathrm{b}$ & 0.068 & 1 & 0.088 & 0.068 & 0.068 & 0.068 & 0.068 & 0.068 & 0.068 & 0.068 \\
\hline c & 0.066 & 0.066 & 1 & 0.066 & 0.066 & 0.066 & 0.066 & 0.066 & 0.066 & 0.066 \\
\hline d & 0.223 & 0.449 & 0.449 & 1 & 0.178 & 0.223 & 0.449 & 0.449 & 0.137 & 0.223 \\
\hline $\mathrm{e}$ & 0.085 & 0.085 & 0.085 & 0.085 & 1 & 0.085 & 0.085 & 0.085 & 0.085 & 0.085 \\
\hline f & 0.214 & 0.427 & 0.285 & 0.142 & 0.171 & 1 & 0.142 & 0.142 & 0.142 & 0.712 \\
\hline $\mathrm{g}$ & 0.223 & 0.670 & 0.268 & 0.142 & 0.171 & 0.223 & 1 & 0.142 & 0.142 & 0.223 \\
\hline h & 0.190 & 0.190 & 0.634 & 0.142 & 0.178 & 0.190 & 0.142 & 1 & 0.142 & 0.190 \\
\hline $\mathrm{i}$ & 0.080 & 0.129 & 0.088 & 0.080 & 0.080 & 0.080 & 0.080 & 0.080 & 1 & 0.129 \\
\hline $\mathrm{j}$ & 0.080 & 0.400 & 0.088 & 0.080 & 0.080 & 0.080 & 0.080 & 0.080 & 0.080 & 1 \\
\hline
\end{tabular}

Table 16 Relative intensity matrix of responsibility

\begin{tabular}{|c|c|c|c|c|c|c|c|c|c|c|}
\hline & $\mathrm{a}$ & $\mathrm{b}$ & $\mathrm{c}$ & $\mathrm{d}$ & $\mathrm{e}$ & $\mathrm{f}$ & $\mathrm{g}$ & $\mathrm{h}$ & $\mathrm{i}$ & $\mathrm{j}$ \\
\hline $\mathrm{a}$ & 1 & 0.229 & 0.206 & 1.000 & 0.229 & 0.229 & 1.000 & 0.229 & 0.014 & 1.000 \\
\hline $\mathrm{b}$ & 0.108 & 1 & 0.108 & 0.598 & 0.108 & 0.108 & 0.239 & 0.108 & 0.014 & 0.478 \\
\hline $\mathrm{c}$ & 0.116 & 0.116 & 1 & 0.232 & 0.116 & 0.116 & 0.232 & 0.116 & 0.014 & 0.465 \\
\hline d & 0.016 & 0.016 & 0.016 & 1 & 0.016 & 0.016 & 0.016 & 0.016 & 0.014 & 0.016 \\
\hline e & 0.108 & 0.168 & 0.108 & 0.168 & 1 & 0.108 & 0.168 & 0.108 & 0.014 & 0.336 \\
\hline $\mathrm{f}$ & 0.056 & 0.056 & 0.056 & 0.056 & 0.056 & 1 & 0.056 & 0.056 & 0.014 & 0.214 \\
\hline $\mathrm{g}$ & 0.090 & 0.090 & 0.090 & 0.360 & 0.090 & 0.090 & 1 & 0.090 & 0.014 & 0.360 \\
\hline $\mathrm{h}$ & 0.200 & 0.200 & 0.200 & 1.000 & 1.000 & 0.889 & 0.222 & 1 & 0.014 & 0.336 \\
\hline $\mathrm{i}$ & 0.056 & 0.056 & 0.056 & 0.056 & 0.056 & 0.056 & 0.056 & 0.056 & 1 & 0.078 \\
\hline $\mathrm{j}$ & 0.056 & 0.056 & 0.056 & 0.056 & 0.056 & 0.056 & 0.056 & 0.056 & 0.014 & 1 \\
\hline
\end{tabular}


F. Blanco-Mesa et al.

Table 17 Relative intensity matrix of salience

\begin{tabular}{lllllllllll}
\hline & $\mathrm{a}$ & $\mathrm{b}$ & $\mathrm{c}$ & $\mathrm{d}$ & $\mathrm{e}$ & $\mathrm{f}$ & $\mathrm{g}$ & $\mathrm{h}$ & $\mathrm{i}$ & $\mathrm{j}$ \\
\hline $\mathrm{a}$ & 1 & 0.256 & 0.214 & 0.515 & 0.214 & 0.214 & 0.461 & 0.214 & 0.088 & 0.618 \\
$\mathrm{~b}$ & 0.211 & 1 & 0.214 & 0.371 & 0.214 & 0.214 & 0.217 & 0.214 & 0.088 & 0.249 \\
$\mathrm{c}$ & 0.19 & 0.19 & 1 & 0.19 & 0.19 & 0.19 & 0.19 & 0.19 & 0.088 & 0.234 \\
$\mathrm{~d}$ & 0.211 & 0.217 & 0.214 & 1 & 0.214 & 0.214 & 0.217 & 0.214 & 0.088 & 0.217 \\
$\mathrm{e}$ & 0.126 & 0.126 & 0.126 & 0.126 & 1 & 0.126 & 0.126 & 0.126 & 0.088 & 0.144 \\
$\mathrm{f}$ & 0.126 & 0.126 & 0.126 & 0.126 & 0.126 & 1 & 0.126 & 0.126 & 0.088 & 0.328 \\
$\mathrm{~g}$ & 0.211 & 0.218 & 0.214 & 0.218 & 0.214 & 0.214 & 1 & 0.214 & 0.088 & 0.218 \\
$\mathrm{~h}$ & 0.211 & 0.217 & 0.44 & 0.47 & 0.564 & 0.484 & 0.217 & 1 & 0.088 & 0.328 \\
$\mathrm{i}$ & 0.095 & 0.095 & 0.095 & 0.095 & 0.095 & 0.095 & 0.095 & 0.095 & 1 & 0.095 \\
$\mathrm{j}$ & 0.126 & 0.126 & 0.126 & 0.126 & 0.126 & 0.126 & 0.126 & 0.126 & 0.088 & 1 \\
\hline
\end{tabular}

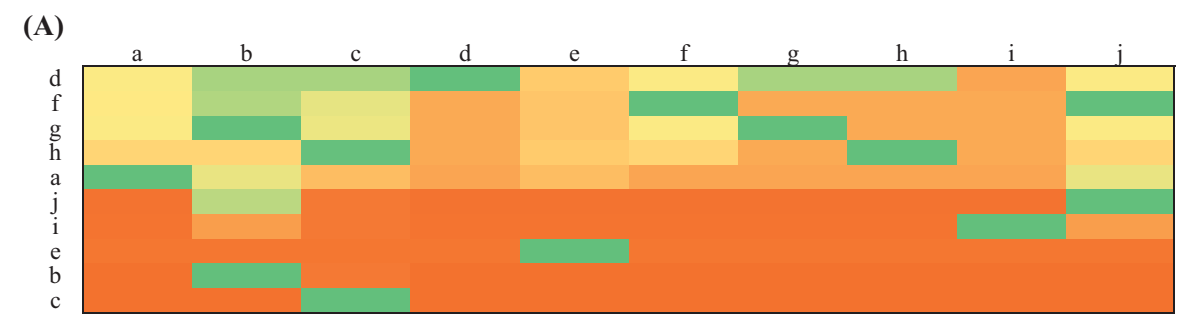

(B)

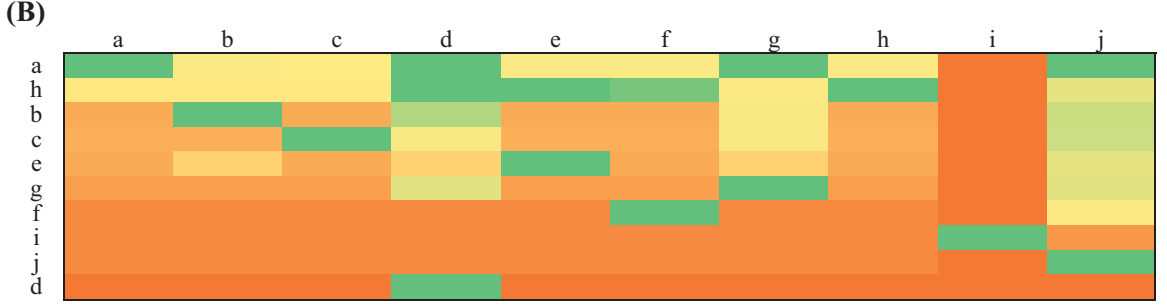

(C)

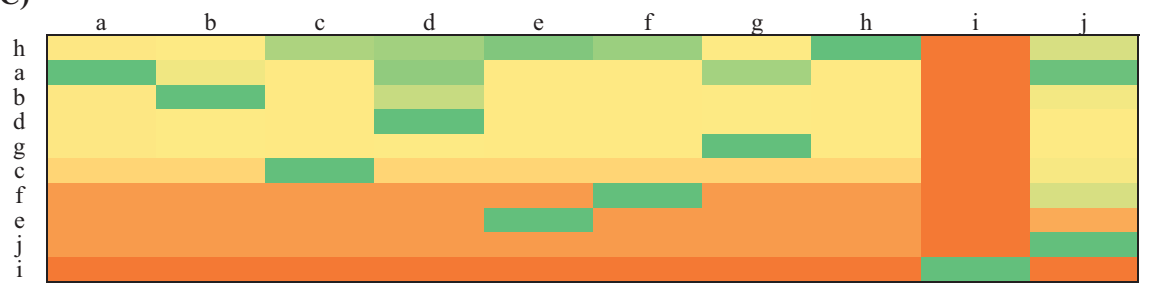

Fig. 2 Graphical representation of each characteristic's intensity. (A) Power relative incidence. (B) Responsibility relative incidence. (C) Salience relative incidence

Table 18 Intensity color code

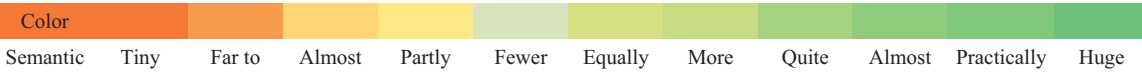


Nevertheless, the results presented in the matrices hinder the practical understanding of the intensity and incidence of the linked relationships among all the stakeholders for each characteristic. Thus, two visual schemes are proposed to portray the dynamics of stakeholder relationships. Figure 2 includes a color representation for each characteristic, showing the intensity of the importance of one stakeholder over another. Here, intensity represents the possible incidence impact that each stakeholder's behavior can have in its relationships on the entire structure and firm. These intensities are determined using minimum, average and maximum limits to configure each matrix of relative intensity. So, in Table 18 is presented the intensity color code to understand intensity

The intensity analysis shows the relative incidence on stakeholder behavior according to its characteristic, where orange color indicates the lowest incidence $\left(\mathrm{L}_{\mathrm{IN}}\right)$, yellow/green color indicates a medium incidence $\left(\mathrm{M}_{\mathrm{IN}}\right)$, and green color indicates the highest incidence $\left(\mathrm{H}_{\mathrm{IN}}\right)$. These incidences denote how some relationships are strengthened and others are degraded as they pass through the sequential stages. Thus, the incidences of $\mathrm{H}_{\mathrm{IN}}$ are more intense than those of $\mathrm{M}_{\mathrm{IN}}$ and $\mathrm{L}_{\mathrm{IN}}$, and the incidence of $\mathrm{M}_{\mathrm{IN}}$ are more intense than those of $\mathrm{L}_{\mathrm{IN}}\left(\mathrm{H}_{\mathrm{IN}}>\mathrm{M}_{\mathrm{IN}}>\mathrm{L}_{\mathrm{IN}}\right)$. For example, in a power-relative incidence, $d$ has an $\mathrm{H}_{\mathrm{IM}}, a$ has an $\mathrm{M}_{\mathrm{IM}}$ and $c$ has an $\mathrm{L}_{\mathrm{IM}}$. In a responsibility-relative incidence, $a$ has an $\mathrm{H}_{\mathrm{IM}}$, $e$ has an $\mathrm{M}_{\mathrm{IM}}$ and $d$ has an $\mathrm{L}_{\mathrm{IM}}$. In a salience-relative incidence, $h$ has an $\mathrm{H}_{\mathrm{IM}}, g$ has an $\mathrm{M}_{\mathrm{IM}}$ and $i$ has an $\mathrm{L}_{\mathrm{IM}}$. These results can be interpreted as showing the responsiveness of a specific stakeholder to environmental pressure. Hence, if the incidence level is high, then the pressure exerted is higher and the pressure received is lower. If the incidence level is low, then the pressure exerted is lower and the pressure received is greater.

(A) Power relative incidence

(B) Responsibility relative incidence

(C) Salience relative incidence

In Fig. 3, each category is represented graphically in which the possible influence between each stakeholder and the firm as unit are denoted in incidence linkage loops (ILL). ILL establishes a relationship order structure using grouping concepts (Gil-Aluja 1999). These concepts allow the determination of linked relationships and equivalent classes through lineal, total order and loop order of indifferent objects. Thus, this structure allows relationship incidences to be indicated at several levels and categories. These graphical representations show loops (circles) and ties (lines); a loop denotes the total relationship of a stakeholder with itself and a tie denotes links that shows the order of each stakeholder at different incidence levels. This analysis is called the linked relationships analysis and differs from that of the intensity of relation because it shows the relative order of stakeholders within different levels and categories.

Here, each level indicates incidence relationships between each stakeholder, where level 1 notes the greatest incidence and level 7 notes the lowest. In fact, incidence levels might weaken or strengthen over a period of time, i.e., they can be significant or non-significant but do not disappear. Likewise, each category 

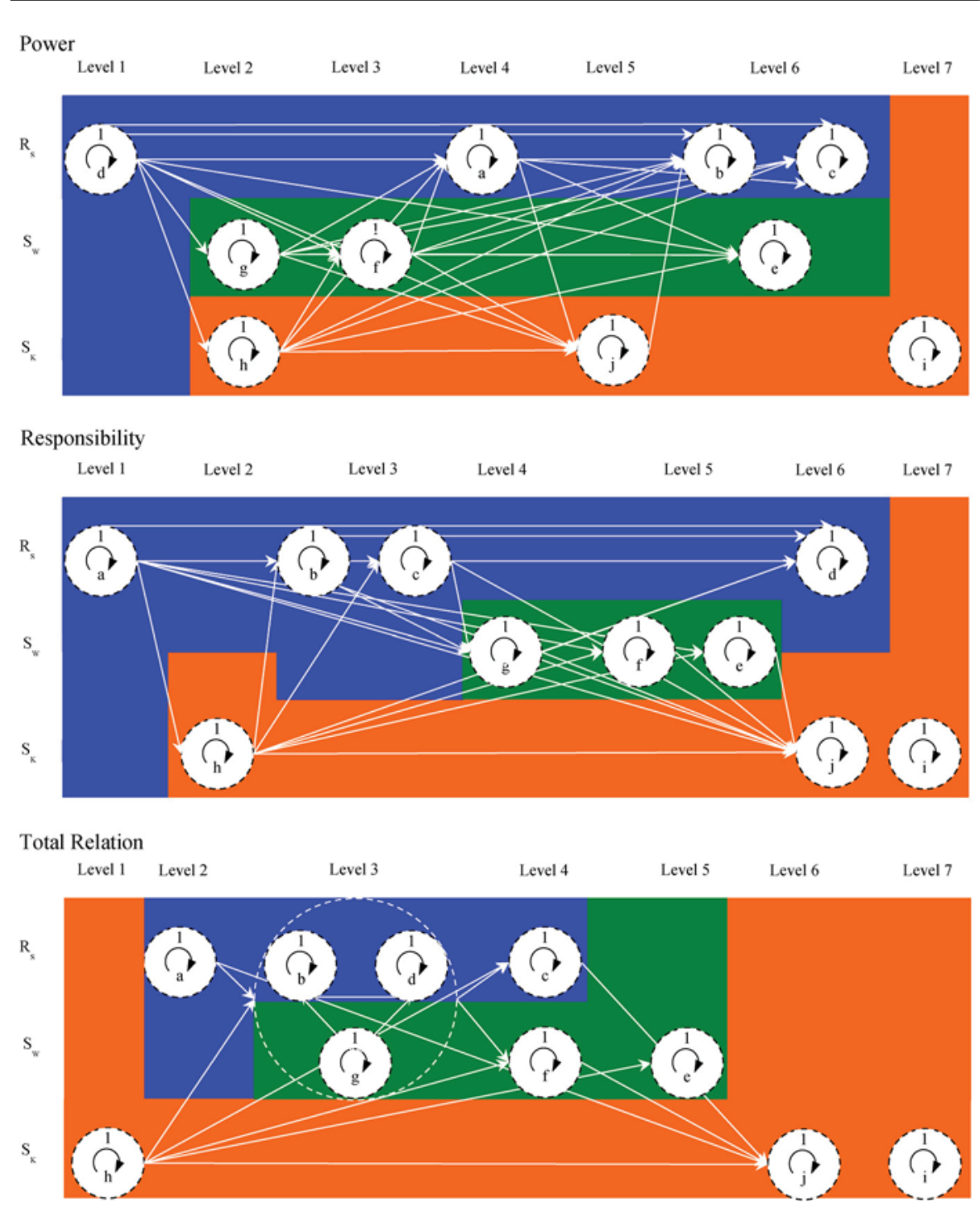

Fig. 3 Stakeholders' incidence linkage loops

defines a relationship class for each stakeholder, where $R_{S}$ represents core firm groups, $S_{W}$ represents the industrial sector to which the firm belongs, and $S_{K}$ represents the firm's social and political arena. Then, the corresponding relationships among stakeholders can be unidirectional and bidirectional. In this sense, graphical representations show the incidence linkage loops to power, responsibility and salience characteristics. Power and responsibility indicate only unidirectional relationships, whereas salience indicates both unidirectional and bidirectional relationships. Thus, the graph interpretation and analysis shows the following: 
First, the graph of power incidences is of great usefulness when decision-makers want to see how much power and influence an agent has over others. Thus, for our hypothetical case's core groups of a firm, $d$ has the greatest power and influence on the other agents belonging to the categories $\mathrm{R}_{\mathrm{S}}, \mathrm{S}_{\mathrm{W}}$ and $\mathrm{S}_{\mathrm{K}}$, whereas $a$ exercises power over $b, c, e$ and $j$ and $f, g$ and $h$ exercise power over $a$. Likewise, $i$ does not have any power incidence, which indicates that it is independent and its behavior is not influenced nor does it exert any influence on the other agents. Hence, $d$ has a great degree of influence and power in the implementation of a new strategic diversification plan. Second, the graph of responsibility incidences is greatly useful when decision-makers want to know the level of incidence on responsibility an agent has over the others. Thus, $a$ has the highest level of responsibility on the whole structure, followed by $h$, whereas the responsibilities of $d$ and $j$ are limited, and $b, c, e, f$ and $g$ have responsibility for specific stakeholders. Hence, $a$ has the highest degree of responsibility in the implementation of a new strategic diversification plan. Third, the graph of salience incidences is greatly useful when decision-makers want to observe in an integral way the incidence between each agent that comprises the stakeholder set. Thus, $h$ has the highest influence on the other agents belonging to the categories $\mathrm{R}_{\mathrm{S}}, \mathrm{S}_{\mathrm{W}}$ and $\mathrm{S}_{\mathrm{K}}$, followed by $a$, whereas $c, d, f$ and $j$ have the lowest influence. Furthermore, $b, e$ and $g$ have formed a strongly connected relation-loop, highlighting their importance within the relational order. Hence, $h$ has the highest degree of influence on the other agents in the implementation of a new strategic diversification plan

\subsection{Implications and limitations}

This research proposes a mathematical approximation providing a methodological approach to analyzing subjective stakeholder dynamics in decision-making processes. This proposition combines several algorithms belonging to the decisionmaking theory in uncertainty, which allows the valuation and analysis of a decisionmaker's subjective preferences when establishing the relationships with different degrees of incidence. In this sense, it contributes in the generation of new methods that allow the establishment of possible incidences that have the agents belonging to the stakeholder set, from the treatment of the perceptions that have the people that comprise them. This method is greatly useful, since the decisions made in stakeholder management are taken by people, which are given by its particular interests when taking advantage of the position of existing power, the responsibilities acquired and the relevance they give to some relationships over others. Within the literature are a wide number of methodologies that allow the stakeholder relationships to be examined. For example, we have shown in the literature review several methods that aid in an understanding of dynamic stakeholder relationships, where the works of Bourne and Walker (2005), Rowley (1997), Rowley and Moldoveanu (2003), Varvasovszky and Brugha (2000), Hjorts $\varnothing$ et al. (2005), Lange and HehlLange (2005), Holz et al. (2006), Memon and Wilson (2007), Finn et al. (2009), Wolsink and Breukers (2010), Fassin (2009; 2010), Windsor (2011) and Elias (2012) are highlighted. However, these tools have boundaries that are difficult to 
define and relevant stakeholders that are hard to identify (Ramirez 1999). In contrast with these proposals, we have proposed a novel method for the treatment of the subjective stakeholder dynamics, in which is considered human reasoning; presented as subjective preferences, as key factor to modify stakeholder behavior in a dynamic and uncertain process, where a firm's decisions can be affected or affects stakeholders. Thus, when subjective preferences change, relationship system between firm's stakeholders is more dynamics and uncertainty losing stability and certainty. Likewise, if in a system take part on a great deal of agents will be more complex. Hence, with this method, the identification of boundaries between each stakeholder is not static and their linked and intensity relationships are relative and dynamic, since they can move among several levels and categories, i.e. position and intensity change by human rationality.

Correspondingly, this work presents several implications that will be useful in future applications for real cases to analyze stakeholders' behavior. Within the phenomena of human nature is the development of mental constructs that relate, assign, group and order information in anticipation of a decision's possible consequences. This process occurs so quickly that the human mind only manages to focus its attention on those elements that are considered important and are expressed in their intentions, preferences and attitudes. Thus, in the decision-making process, this lack of attention is a bias that leads to a great loss of information. Based on this premise, a mathematical tool is developed that allows collecting these subjective assessments to be processed without forgetting information that may be relevant. In this sense, this tool is presented in an example to predict possible behaviors and the intensity of the relations among stakeholders, focusing on the company.

First, a mathematical method is presented that allows a predictive simulation tool to be made about attitude and personal preferences based on a mathematical assumption for subjective preference. This methodology can aggregate subjective information to determine the incidence, edges and behavior of relationships among stakeholders according to each characteristic's intensity. Intensity is established using algorithms belonging to fuzzy systems, which are able to process agents' personal interests that comprise stakeholders through the valuations that capture their opinions, perceptions and attitudes. Second, as a result of information processing, the main outputs are obtained that are the matrices of relative intensity that allow us to build the groupings and relationships between each stakeholder. These products are of great importance because they offer theoretically sustainable results on the treatment of subjectivity using non-parametric techniques, an aspect that is difficult to predict using parametric techniques. Third, on the mathematical assumption of the methodological application, the multiple relationships network can be weakened or strengthened according to power/influence, responsibility, legality and salience positions. On the one hand, multiple relationships are characterized by their high degree of variation in the relationship intensity, which explains its heterogeneity. On the other hand, a position refers to groups or individuals who can affect or be affected by the organization according to the relationship's pragmatic aspects between the stakeholders and the firm, i.e., a relationship determined by the market (Fassin 2009; Freeman 2011). Hence, analyzing stakeholder dynamics in the decision-making process implies how a firm's decisions or actions can be affected or affect stakeholders 
considering uncertain environmental factors like policies, economics, social, environment and technological changes globally. In this sense, these dynamics can promote or restrict trust and cooperation affecting competitiveness, productivity, transfer of knowledge, the conformation of strategic alliances and so on.

On the other hand, it is important to mention that in the literature there are similar methods to allow comparing information. One of this is Analytical Hierarchy Process (AHP), which allow comparison taking into account measurements or scales to reflects the relative strength of preferences and feelings the analytic hierarchy process (Saaty 1987). In AHP is presented an eigenvector solution for weights, where weighted vectors normalization help to get priority vector. In the proposition presented, algorithms stated in Definitions 1,2 and 3 are used to obtain eigenvalue and eigenvector to build fuzzy relative matrices $\left(\mathrm{FR}_{\mathrm{M}}\right)$ and intensity relative matrices $\left(\mathrm{IR}_{\mathrm{M}}\right)$. Hence, in this paper is used to get final results definitive results and not as a previous step or creation of the priority vector. Likewise, (Yager 1988, 1993) has proposed new methods to get weighted vectors through entropy of dispersion, Balance operator, divergence of $\mathrm{W}$ and degree of orness, which can be used to obtain subjective preferences for futures researches.

However, this research has limitations due to this study's nature. A prominent limitation is the empirical validation of the research itself, since a mathematical method is proposed whose application is a supposition to prove its theoretical operation. Similarly, as a mathematical proposition, methodological limitations exist because it is presented as a hypothetical example to illustrate the operation of algorithms to show how the assumption subjective preference is parameterized. Hence, these methodological limitations are evident, as they are used as important elements in the stakeholder theory to elaborate the hypothetical examples to study the stakeholder's relationships and their implications when making a decision.

\section{Conclusions}

We study stakeholder theory and briefly review developed stakeholder analysis tools to evaluate the environment and identify the relations among groups that constitute stakeholders. Likewise, we highlight the changing relationships among stakeholders in a dynamic and uncertain process. We also briefly review fuzzy decision-making and its application in business studies. We highlight the methodology developed by Gil-Aluja (1999), which explores the broad notion of relation using the importanceof-characteristics-ordering and linking-of-relations methods. We propose a novel method that makes a predictive simulation tool about attitude and personal preferences based on a mathematical assumption subjective preference. We present a numerical example to demonstrate the proposed method's usefulness and feasibility. The numerical example is focused on a mathematical assumption for the treatment of stakeholder relationships, which considers the P, L, and R characteristics and the $\mathrm{Rs}, \mathrm{Sw}$ and Sk categories for an environment of uncertainty. The main advantage of using this method is that it can parameterize the importance of information about each characteristic according to the decision-maker's preferences Additionally, 
subjective information is provided by experts who possess knowledge but do not know the effect of their decisions.

Results of the numerical mathematical assumption subjective preference example allow the fuzzy subjective preference and relative intensity to be obtained between each stakeholder. These results are depicted to show the intensity of the stakeholders' importance and their incidence linkage loops. Likewise, the graphical representation allows an interpretation to be obtained of the responsiveness and significant level of a specific stakeholder's incidence. The mathematical tool application is developed that allows these collected subjective assessments to be processed without forgetting information that may be relevant. First, the method allows a predictive simulation tool to be made about attitude and personal preferences. Furthermore, it offers theoretically sustainable results on the treatment of subjectivity using nonparametric techniques, an aspect that is difficult to predict using parametric techniques. Hence, analyzing subjective stakeholder dynamics in the decision-making process implies how a firm's decisions or actions can be affected or affects stakeholders considering uncertain environment factors.

However, this research has limitations due to the study's nature as empirical and methodological validation, since a hypothetical example was used based on important elements in stakeholder theory. Likewise, the model continues to be fully valid, and specific results will evolve in the medium and long term according to the functional trend that the dynamic process itself will provide. In future studies, this novel methodology can be applied in stakeholder case studies to understand its applicability and scope.

Acknowledgements We would like to thank the anonymous reviewers for valuable comments that have improved the paper's quality.

\section{References}

Atanassov KT (1986) Intuitionistic fuzzy sets. Fuzzy Sets Syst 20:87-96

Bellman RE, Zadeh LA (1970) Decision-making in a fuzzy environment. Manag Sci 17:B-141-B-164

Blanco-Mesa F (2015) Técnicas para la toma de decisiones en contextos inciertos: identificación de oportunidades socio- económicas en el ámbito deportivo. Universitat de Barcelona, Barcelona

Blanco-Mesa F, Gil-Lafuente AM (2014) Characterization and grouping of the Colombia regions for development of clusters: An application of the Pichat algorithm. J Comput Optim Econ Financ 5:187-196

Blanco-Mesa F, Gil-Lafuente AM (2017) Towards a competitiveness in the economic activity in Colombia: using Moore's families and Galois latticies in clustering. Econ Comput Econ Cybern Stud Res 51:231-250

Blanco-Mesa F, Gil-Lafuente AM, Merigó JM (2015) New aggregation methods for decision-making in the selection of business opportunities. In: Gil-Aluja J, Terceño-Gomez A, Ferrer-Comalat JC et al (eds) Scientific methods for the treatment of uncertainty in social science. Springer International Publishing, Girona, pp 3-18

Blanco-Mesa F, Merigó JM, Gil-Lafuente AM (2017) Fuzzy decision making: a bibliometric-based review. J Intell Fuzzy Syst 32:2033-2050

Blanco-Mesa F, Gil-Lafuente AM, Merigó JM (2018) New aggregation operators for decision-making under uncertainty: an applications in selection of entrepreneurial opportunities. Technol Econ Dev Econ 24:335-357

Bourne L, Walker DHT (2005) Visualising and mapping stakeholder influence. Manag Decis 43:649-660 
Carlsson C, Fullér R (1996) Fuzzy multiple criteria decision making: recent developments. Fuzzy Sets Syst 78:139-153

Chen SJ, Hwang CL (1992) Fuzzy multiple attribute decision making: methods and applications. Springer, Berlin

Donaldson T, Preston LE (1995) The stakeholder theory of the corporation: concepts, evidence and implications. Acad Manag Rev 20:65-91

Elias AA (2012) A system dynamics model for stakeholder analysis in environmental conflicts. J Environ Plan Manag 55:387-406

Fassin Y (2007) Imperfections and shortcomings of the stakeholder model's graphical representation. J Bus Ethics 80:879-888

Fassin Y (2009) The stakeholder model refined. J Bus Ethics 84:113-135. https://doi.org/10.1007/s1055 $1-008-9677-4$

Fassin Y (2010) A dynamic perspective in Freeman's stakeholder model. J Bus Ethics 96:39-49

Finn JA, Bartolini F, Bourke D et al (2009) Ex post environmental evaluation of agri-environment schemes using experts' judgements and multicriteria analysis. J Environ Plan Manag 52:717-737

Freeman RE (1984) Strategic management: a stakeholder approach. Pitman, Boston

Freeman RE (2004) The stakeholder approach revisited. Zeitschrift für Wirtschafts und Unternehmensethik 5:228-241

Freeman RE (2011) Managing for stakeholders: trade-offs or value creation. J Bus Ethics 96:7-9

Friedman AL, Miles S (2002) Developing stakeholder theory. J Manag Stud 39:1-21

Frooman J (1999) Stakeholder influence strategies. Acad Manag Rev 24:191-205

Gil-Aluja J (1996) Towards a new paradigm of investment selection in uncertainty. Fuzzy Sets Syst 84:187-197

Gil-Aluja J (1999) Elements for a theory of decision in uncertainty. Kluwer Academic Publishers, Dordrech

Gil-Aluja J (2000) Lances y desventuras del nuevo paradigma de la teoría de la decisión. Proceedings del III Congreso SIGEF. SIGEF, Buenos Aires, pp 11-37

Gil-Lafuente J (1997) Marketing para el nuevo milenio: Nuevas técnicas para la gestión comercial en la incertidumbre. Ediciones Pirámide, Barcelona

Gil-Lafuente J (2001) Algoritmos para la excelencia: Claves para el éxito en la gestión deportiva. Barcelona Editions, Barcelona, F.C

Gil-Lafuente J (2002) Keys for success in sport management. Ed. Malladoiro, Vigo

Gil-Lafuente J (2008) Automatismos y racionalidad en la toma de decisiones para sustituir a un deportista en momentos decisivos. Cuad gestión 8:39-57

Gil-Lafuente AM, Barcellos de Paula L (2010) Una aplicación de la metodología de los efectos olvidados: Los factores que contribuyen al crecimiento sostenible de la empresa. Cuad del CIMBAGE $12: 23-34$

Gil-Lafuente AM, Barcellos de Paula L (2013) Algorithm applied in the identification of stakeholders. Kybernetes 42:674-685

Gil-Lafuente AM, Luis Bassa C (2011) The forgotten effects model in a CRM strategy. Fuzzy Econ Rev 16:3-19

Gil-Lafuente AM, Klimova A, Imanov K (2012a) Forgotten effects in the comparative economic analysis for Spain and Russia in conditions of globalization. In 2012 IV international conference "problems of cybernetics and informatics" (PCI). IEEE, Baku, pp 1-4

Gil-Lafuente AM, Blanco-Mesa F, Castillo C (2012b) The forgotten effects of sport. In: Gil-Lafuente AM, Gil-Lafuente J, Merigó-Lindahl JM (eds) Soft computing in management and business economics. Springer, Berlin Heidelberg, Berlin, Heidelberg, pp 375-391

He X, Wu Y, Yu D, Merigó JM (2017) Exploring the ordered weighted averaging operator knowledge domain: a bibliometric analysis. Int J Intell Syst 32:1151-1166

Hjortsø CN, Christensen SM, Tarp P (2005) Rapid stakeholder and conflict assessment for natural resource management using cognitive mapping: the case of Damdoi Forest Enterprise, Vietnam. Agric Human Values 22:149-167

Holz L, Kuczera G, Kalma J (2006) Multiple criteria decision making: facilitating a learning environment. J Environ Plan Manag 49:455-470

Holzer B (2007) Turning stakeseekers into stakeholders: a political coalition perspective on the politics of stakeholder influence. Bus Soc 47:50-67

Hwang C-L, Yoon K (1981) Multiple attribute decision making. Springer, Berlin Heidelberg

Kacprzyk J (1986) Group decision making with a fuzzy linguistic majority. Fuzzy Sets Syst 18:105-118 
Kaufmann A, Gil-Aluja J (1988) Modelos para la investigación de los efectos olvidados. Milladoiro, Vigo

Kaufmann A, Gil-Aluja J (1991) Nuevas técnicas para la dirección estratégica. Publicacions Universitat de Barcelona, Barcelona

Kaufmann A, Gil-Aluja J (1992) Técnicas de gestión de empresa: previsiones, decisiones y estrategias. Ediciones Pirámide

Kaufmann A, Gil-Aluja J (1993) Técnicas especiales para la gestión de expertos. Villadoiro, Vigo

Kaufmann A, Gil-Aluja J (1995) Grafos Neuronales para la Economía y la Gestión de Empresas. Ediciones Pirámide, Madrid

Kaufmann A, Gil-Aluja J, Gil-Lafuente AM (1994) La creatividad en la gestión de las empresas. Ediciones Pirámide, Madrid

Kochenderfer MJ (2015) Decision making under uncertainty: theory and application. MIT Lincoln Laboratory Series, Cambrige

Laengle S, Loyola G, Merigo JM (2017) Mean-variance portfolio selection with the ordered weighted average. IEEE Trans Fuzzy Syst 25:350-362

Lange E, Hehl-Lange S (2005) Combining a participatory planning approach with a virtual landscape model for the siting of wind turbines. J Environ Plan Manag 48:833-852

León-Castro E, Avilés-Ochoa E, Merigó JM, Gil-Lafuente AM (2018) Heavy moving averages and their application in econometric forecasting. Cybern Syst 49:26-43

Maqueda Lafuente JF, Gil-Lafuente AM, Guzman-Parra VF, Gil-Lafuente J (2013) Key factors for entrepreneurial success. Manag Decis 51:1932-1944

Martorell-Cunill O, Gil-Lafuente AM, Socias Salvà A, Mulet Forteza C (2013) The growth strategies in the hospitality industry from the perspective of the forgotten effects. Comput Math Organ Theory 20:195-210

Memon PA, Wilson GA (2007) Contesting governance of indigenous forests in New Zealand: the case of the West Coast Forest Accord. J Environ Plan Manag 50:745-764

Merigó JM, Gil-Lafuente AM (2009) The induced generalized OWA operator. Inf Sci (Ny) 179:729-741

Merigó JM, Gil-Lafuente AM, Yager RR (2015) An overview of fuzzy research with bibliometric indicators. Appl Soft Comput 27:420-433

Mitchell RK, Agle BR, Wood DJ (1997) Toward a theory of stakeholders identification and salience: defining the principle of who and what really. Acad Manag Rev 22:853-886

Nicolás C, Gil-Lafuente J (2012) Customer experience assessment: forgotten effects. J Comput Optim Econ Financ 4:77-88

Post JE, Preston LE, Sachs S (2002) Managing the extended enterprise: the new stakeholder view. Calif Manage Rev 45:6-28

Ramirez R (1999) Stakeholder analysis and conflict management. In: Buckles D (ed) Cultivating peace: conflict and collaboration in. World Bank Institute, Whasintong, pp 101-126

Rowley TJ (1997) Moving beyond dyadic ties: a network theory of stakeholder influences. Acad Manag Rev 22:887-910

Rowley TI, Moldoveanu M (2003) When will stakeholder groups act? An interest and identity: based model of stakeholder group mobilization. Acad Manag Rev 28:204-219

Saaty TL (1980) Analytical hierarchy process. McGraw-Hill, New York

Saaty RW (1987) The analytic hierarchy process: what it is and how it is used. Math Model 9:161-176

Saaty TL (1990) How to make a decision: the analytic hierarchy process. Eur J Oper Res 48:9-26

Salazar-Garza R (2012) The mexican peso: exchange risk coverage management through the forgotten effects theory. J Econ Financ Adm Sci 17:53-73

Sciarelli M, Tani M (2013) Network approach and stakeholder management. Bus Syst Rev 2:175-190

Stave KA (2002) Using system dynamics to improve public participation in environmental decisions. Syst Dyn Rev 18:139-167

Tanino T (1984) Fuzzy preference orderings in group decision making. Fuzzy Sets Syst 12:117-131

Tzeng GH, Huang JJ (2011) Multiple attribute decision making: methods and applications. Chapman and Hall/CRC, Boca Raton

Varvasovszky Z, Brugha R (2000) A stakeholder analysis. Health Policy Plan 15:338-345

Vizuete Luciano E, Gil-Lafuente AM, García González A, Boria-Reverte S (2013) Forgotten effects of corporate social and environmental responsibility. Kybernetes 42:736-753

Waddock S (2011) We are all stakeholders of Gaia: a normative perspective on stakeholder thinking. Organ Environ 24:192-212

Wagner E, Alves H, Raposo M (2011) Stakeholder theory: issues to resolve. Manag Decis 49:226-252

Windsor D (2011) The role of dynamics in stakeholder thinking. J Bus Ethics 96:79-87 
Winn MI (2001) Building stakeholder theory with a decision modeling methodology. Bus Soc 40:133-166 Wolsink M, Breukers S (2010) Contrasting the core beliefs regarding the effective implementation of wind power. an international study of stakeholder perspectives. J Environ Plan Manag 53:535-558

Xu Z (2015) Uncertain multi-attribute decision making: Methods and applications. Springer, Berlin

Yager RR (1988) On ordered weighted averaging aggregation operators in multicriteria decision-making. IEEE Trans Syst Man Cybern 18:183-190

Yager RR (1993) Families of OWA operators. Fuzzy Sets Syst 59:125-148

Zadeh LA (1965) Fuzzy sets. Inf Control 8:338-353

Zadeh LA (1975a) The concept of a linguistic variable and its application to approximate reasoning I. Inf Sci (Ny) 8:199-249

Zadeh LA (1975b) The concept of a linguistic variable and its application to approximate reasoning II. Inf Sci (Ny) 8:301-357

Zadeh LA (1975c) The concept of a linguistic variable and its application to approximate reasoning III. Inf Sci (Ny) 9:43-80

Zadeh LA (1999) Fuzzy sets as a basis for a theory of possibility. Fuzzy Sets Syst 100:9-34

Zimmermann HJ (1978) Results of empirical studies in fuzzy set theory. Plenum Press, New York

Zimmermann HJ (1986) Fuzzy sets, decision making and expert systems. Kluwer Academic Publishers, Netherlands

Zimmermann HJ, Zadeh L, Gaines B (1984) Fuzzy sets and decision analysis. North-Holland, Amsterdam

Fabio Blanco-Mesa is a PhD student at the Department of Business Administration at the University of Barcelona, Spain. He also holds a Bachelor from the District University Francisco Jose of Caldas and an MSc in Business Research from the University of Barcelona. He has published several papers in international journals, books and conference proceedings including International Journal of Intelligent Systems, Knowledge-Based Systems, Kybernetes, Applied Soft Computing and Technological and Economic Development of Economy. He also serves as a reviewer for several international journals. He is currently interested in Decision Making, Entrepreneurship, Competitiveness, Fuzzy Systems, Aggregation Operators, Strategy, Stakeholders, Sport Management and Uncertainty.

Anna María Gil-Lafuente is a Professor in the Department of Business Administration at the University of Barcelona (Spain). She has an MSc and a PhD Degree in Business Administration from the University of Barcelona. She has published more than 450 papers in journals, books and conference proceedings including journals such as Information Sciences, International Journal of Intelligent Systems, Applied Soft Computing, International Journal of Uncertainty, Fuzziness and Knowledge-Based Systems and Expert Systems with Applications. She has published more than 20 books including 10 with Springer and 2 with World Scientific. She is editor-in-chief of Nova Sciences Collection Computational Intelligence in Engineering, Economics, and Management and co-editor-in-chief of 8 journals published by the Association for Modeling and Simulation in Enterprises (AMSE). She is on the editorial board of several journals and scientific committees. She has also served as a reviewer for many journals. She is currently interested in Decision Making, Aggregation operators, Fuzzy Systems, Uncertainty and Finance.

José M. Merigó is a Professor at the Department of Management Control and Information Systems at the University of Chile. Previously, he was a Senior Research Fellow at the Manchester Business School, University of Manchester (UK) and an Assistant Professor in the Department of Business Administration at the University of Barcelona (Spain). He has a MSc and a PhD degree in Business Administration from University of Barcelona, Spain. He also holds a Bachelor Degree in Economics and a Master Degree in European Business Administration and Business Law from Lund University, Sweden. He has published more than 300 papers in journals, books and conference proceedings including journals such as Information Sciences, European Journal of Operational Research, Technological and Economic Development of Economy, Expert Systems with Applications, International Journal of Intelligent Systems and Computers \& Industrial Engineering. He has published 10 books including four with Springer and two with World Scientific. He is on the editorial board of several journals including the Journal of Business Research, Technological and Economic Development of Economy, Journal of Intelligent \& Fuzzy Systems and Economic Computation and Economic Cybernetics Studies and Research. He has participated in several scientific committees and serves as a reviewer in a wide range of journals. He is currently interested in Aggregation Operators, Decision Making, Uncertainty and Bibliometrics. 


\section{Affiliations}

\section{Fabio Blanco-Mesa ${ }^{1}\left(\mathbb{1} \cdot\right.$ Anna María Gil-Lafuente $^{2} \cdot$ José M. Merigó $^{3}$}

Anna María Gil-Lafuente

amgil@ub.edu

José M. Merigó

jmerigo@fen.uchile.cl

1 Universidad Pedagógica y Tecnológica de Colombia, Av. Central del Norte 39-115,

Tunja 150001, Boyacá, Colombia

2 University of Barcelona, Av. Diagonal, 690, 08034 Barcelona, Spain

3 Department of Management Control and Information Systems, School of Economics and Business, University of Chile, Av. Diagonal Paraguay 257, 8330015 Santiago, Chile 